\title{
Immigrant biculturalism: A qualitative study of two groups of Polish-Canadians
}

\author{
by \\ Andrzej Szeib
}

A thesis submitted to the Faculty of Graduate Studies and Postdoctoral Affairs in partial fulfilment of the requirements for the degree of

Master of Arts

in

Applied Linguistics and Discourse Studies

Carleton University

Ottawa, Ontario

()ำ 2011

Andrzej Szeib 
Library and Archives

Canada

Published Heritage Branch

395 Wellington Street

Ottawa ON K1A ON4

Canada
Bibliothèque et

Archives Canada

Direction du

Patrimoine de l'édition

395 , rue Wellington

Ottawa ON K1A ON4

Canada
Your file Votre référence

ISBN: 978-0-494-83111-3

Our file Notre référence

ISBN: 978-0-494-83111-3
NOTICE:

The author has granted a nonexclusive license allowing Library and Archives Canada to reproduce, publish, archive, preserve, conserve, communicate to the public by telecommunication or on the Internet, loan, distribute and sell theses worldwide, for commercial or noncommercial purposes, in microform, paper, electronic and/or any other formats.

The author retains copyright ownership and moral rights in this thesis. Neither the thesis nor substantial extracts from it may be printed or otherwise reproduced without the author's permission.
AVIS:

L'auteur a accordé une licence non exclusive permettant à la Bibliothèque et Archives Canada de reproduire, publier, archiver, sauvegarder, conserver, transmettre au public par télécommunication ou par l'Internet, prêter, distribuer et vendre des thèses partout dans le monde, à des fins commerciales ou autres, sur support microforme, papier, électronique et/ou autres formats.

L'auteur conserve la propriété du droit d'auteur et des droits moraux qui protège cette thèse. $\mathrm{Ni}$ la thèse ni des extraits substantiels de celle-ci ne doivent être imprimés ou autrement reproduits sans son autorisation.
In compliance with the Canadian Privacy Act some supporting forms may have been removed from this thesis.

While these forms may be included in the document page count, their removal does not represent any loss of content from the thesis.
Conformément à la loi canadienne sur la protection de la vie privée, quelques formulaires secondaires ont été enlevés de cette thèse.

Bien que ces formulaires aient inclus dans la pagination, il n'y aura aucun contenu manquant.

\section{Canadä}




\begin{abstract}
This qualitative study looks at how two groups of Polish-Canadian biculturals those who immigrated to Canada as adolescents and those who immigrated as adults construct their bicultural identities within a multicultural context. Data gathered through semi-structured interviews suggest that the construction of bicultural identities is complex and dynamic. The findings suggest that currently used, largely quantitative typologies insufficiently account for the intricacies of biculturalism and need to be supplemented by theoretical and qualitative work on social networks, language and identity, and bilingualism. The analysis indicates that individual biculturalism is greatly shaped by the context. More specifically, the participants' image of multicultural Canada is integral in forming their bicultural identities. In addition, language was found to be a salient aspect of biculturalism, especially in shaping and reflecting the duality inherent in the bicultural experience.
\end{abstract}




\section{ACKNOWLEDGEMENTS}

I owe my deepest gratitude to my supervisor, Ellen Cray, for her support, encouragement, and endless patience during this long and often painful process. Without our numerous meetings, emails, phone calls, and Skype conversations, I would likely still be in the beginning stages of the writing process. Without her numerous edits, the quality of this work would be far less than what it is. Please accept my apologies for the dozens of modals superfluously scattered throughout - to the best of my knowledge, there might only be a few left.

I must also apologize to Aurélie for constantly torturing her with my prose, and to whom I am forever grateful for her careful proofreading, insightful advice on content, structure, and style, and enduring support during those numerous moments of weakness when, not quite standing (nor sitting), I would exclaim, “I can't do it!" Thank you for having the strength to get me off the floor.

I am indebted to Jaffer Sheyholislami, for pointing me in the right direction on matters of language and identity and offering helpful advice during various stages of this process. I also thank Jonathan Luke for the numerous exchanges of books and ideas.

Many thanks to my participants who so willingly took the time to share with me their very personal experiences and whose perspectives on biculturalism have helped me see mine in a new light, and without whose insightful input this thesis would not exist.

Finally, to my family - dziękuje Wam, kochani. 


\section{TABLE OF CONTENTS}

ABSTRACT

ACKNOWLEDGEMENTS

TABLE OF CONTENTS iv

LIST OF APPENDICES vi

CHAPTER I: INTRODUCTION 1

CHAPTER II: UNDERSTANDING BICULTURALISM 6

1. The marginal model 6

$\begin{array}{lr}\text { 2. The biculturalist approach } & 10\end{array}$

3. Biculturalism in acculturation research 24

4. Language and identity 37

5. Studies of Polish immigrants 48

CHAPTER III: METHODOLOGY

$\begin{array}{lr}\text { 1. Participants } & 60\end{array}$

2. Data collection $\quad 62$

$\begin{array}{lc}\text { 3. Data analysis } & 63\end{array}$

4. Managing bias: The role of the researcher 65

CHAPTER IV: RESULTS AND DISCUSSION 67

1. Participant biographies $\quad 68$

1.1 Adolescent group $\quad 68$

$\begin{array}{ll}1.2 \text { Adult group } & 69\end{array}$

2. Cultural identity: Ethnic versus national 70

2.1 Constructing Polish (ethnic) identity 70

2.2 Constructing Canadian (national) identity 78

2.3 Overview of cultural identity $\quad 84$ 
3. Biculturalism

3.1 Hyphenated identity

3.2 Living in (between) two cultures

3.3 Social networks

4. Discussion

CHAPTER V: CONCLUSION

REFERENCES

112

APPENDICES

Appendix A

Appendix B

Appendix C

Appendix D 


\section{LIST OF APPENDICES}

Appendix A: Consent form and letter of information

Appendix B: Biographical questionnaire

Appendix C: Interview questions

120

Appendix D: Ethics clearance form

121 


\section{CHAPTER I: INTRODUCTION}

The study of biculturalism is concerned with what happens to individuals in extended cross-cultural contact. The field, however, is quite small and the phenomenon remains largely understudied (Benet-Martínez, 2005; De Korne et al., 2007). More specifically, biculturalism has been predominantly examined by researchers working in social psychology, often within the framework of acculturation. Some examples of work done in this area include Berry (2005), Phinney, Berry, Vedder and Liebkind (2006), and Tartakovsky (2009). These works look at immigrant acculturation using Berry's (1980) model of acculturation and Phinney's (1992) measurement of ethnic and national identities. Other researchers working within psychology look at cognitive/behavioural aspects of bicultural identity, exploring how the two cultural identities are internalized and expressed (Benet-Martínez, Leu, Lee, \& Morris, 2002; Hong, Morris, Chiu, and Benet-Martínez, 2000). These researchers distinguish between biculturals with 'integrated' identities and those with 'conflicting' identities.

Perhaps the most influential work on biculturalism within psychology has been done by LaFromboise, Coleman, and Gerton (1993), Phinney (1990, 1992), Phinney, Cantu, and Kurtz (1997), and Phinney and Devich-Navarro (1997). LaFromboise et al. (1993) offer a comprehensive review of literature on cultural acquisition and propose the biculutural competence construct (BCC), outlining a number of characteristics of 'healthy' biculturalism. Phinney and colleagues' cultural dichotomy between ethnic and national identity offers a simple framework for the study of bicultural identity. They argue that the bicultural experience is marked by identifying with the culture of origin (ethnic identity) and the culture of the majority (national identity). These researchers 
study the relative strength of the two identities and their effect on individuals' psychological well-being and argue that a strong ethnic identity coupled with a strong national identity is the 'best' combination for a 'healthy' biculturalism. The studies mentioned here propagate a non-linear understanding of cultural acquisition where it is possible, and even desirable, to maintain links with more than a single culture, where the acquisition of one does not have to be coupled with the attrition of the other.

In fact, all of the work mentioned thus far reflects this paradigm of cultural acquisition and can be viewed as a celebration of both social and personal multiculturalism. This approach is often contrasted with older 'assimilationist' or 'bipolar' models of cultural acquisition that claim that existing in two cultures is a source of psychological stress and that acquisition of one must come at the cost of losing the other. Often used as an example of this is the work of Park (1928) who claims that those who exist within two cultures are condemned to the margins of society and remain forever torn between two worlds.

The research on biculturalism discussed so far is also characterized by being either largely non-empirical or mostly quantitative. The latter approach reduces the notion of culture and identity to oversimplified quantitative constructs, giving an incomplete picture of biculturalism.

I begin this study by critically examining the existing literature on biculturalism (in Chapter II). Section 1 describes Park's (1928) marginal model, its limitations and the criticism it has received since its inception. Section 2 centres around LaFromboise et al.'s (1993) theoretical paper on bicultural competence, supplemented, where possible, with findings from more recent empirical studies on bicultural identity. Section 3 offers a 
review of biculturalism in acculturation research and discusses the limitations of this approach. Section 4 is an attempt to broaden the discussion of biculturalism beyond the existing typologies by examining the role of language in shaping group and individual identities. To do this I draw on the work on language and identity done by Fishman (1989, 1993), May (2002), Joseph (2004), and Edwards (2009). The discussion of language in this section also draws on research on bilingualism, particularly the work of Pavlenko $(2005,2006)$ and Grosjean (2010). The chapter concludes with a review of studies on Polish immigrants and illustrates that this group has not been studied very extensively, particularly within the Canadian context.

\section{Rationale for conducting this study}

In 2006, 191 million people lived outside of their countries of origin, a rise from 155 million in 1990 (United Nations, 2009a). In 2009, the number of migrants increased to 213 million, or 3 percent of the global population (United Nations, 2009b). As the world becomes smaller due to globalization, transnational migration is projected to continue rising. Though the current global percentage of migrants remains relatively low (at 3 percent), the numbers are significantly higher for immigrant-receiving nations such as Canada.

In 2006, 6.5 million Canadians were first generation immigrants. In other words, approximately 20 percent of the country's population was born outside of Canada (Statistics Canada, 2011). These numbers continue to increase each year, as Canada's immigrant intake remains high, with more than 280000 newcomers welcomed in 2010 alone (Citizenship and Immigration Canada, 2011). Both global and local trends suggest that an increasing number of people are faced with the acquisition of additional cultures. 
Consequently, cultural identities are becoming more complex and multiple with large numbers of people grounded in multiple cultures. Because of this, the study of biculturalism is particularly relevant in today's globalized world.

There are approximately 200000 first-generation Polish immigrants currently living in Canada and nearly a million Canadian citizens who are of Polish ethnic heritage. Even though Polish migration to Canada mostly ended by 1995, Polish immigrants are still amongst the largest groups of foreign-born Canadians (Statistics Canada, 2011). Despite this, there has been very little research published on their experiences and there appears to be only one recent empirical study on Polish immigrant identity (Lustanski, 2009). My study, therefore, attempts to enhance the understanding of Polish-Canadians and seems to be the first to do so using the framework of biculturalism and a qualitative methodology. ${ }^{1}$

Further, this study is unique because it looks at two different groups of biculturals: those who arrived in Canada as adults and those who arrived in Canada as adolescents. Though the sample is too small (three participants in each group) to make effective comparisons, the findings can be treated as a preliminary look at the variations that might exist between these groups.

The reasons for studying Polish immigrants are also personal since that is what I am - a Polish-Canadian. In a way, then, this study - conducted in order to better understand Polish biculturalism - is an attempt to better understand myself.

With the aforementioned in mind, I address the following research questions:

\footnotetext{
${ }^{1}$ Other qualitative studies of Polish immigrants exist and are reviewed in Chapter II. However, both Temple (2010) and Ryan (2010) study Poles in England and use a different framework.
} 
1. How effectively do existing frameworks describe biculturalism? More specifically, does the existing literature on biculturalism apply to the experiences of my participants?

2. How do these Polish biculturals negotiate, or construct, their bicultural identities?

3. Is language a salient marker of bicultural identity for these participants? 


\section{CHAPTER II: UNDERSTANDING BICULTURALISM}

"The train cuts through endless expanses of terrain, most of it flat and monotonous, and it seems to me that the relentless rhythm of the wheels is like scissors cutting a threethousand-mile rip through my life. From now on, my life will be divided into two parts..." (Hoffman, 1989, p. 100)

In her memoir, Lost in Translation: A Life in a New Language, Eva Hoffman, recalling her immigration experience, insightfully examines the long and painful transformation from a monocultural to a bicultural self. Her train-ride across Canada in 1959 marks the beginning of that process, the beginning of a struggle to integrate her Polish and Anglo identities. There is much in Hoffman's story that will be familiar to immigrants who upon arriving in an unfamiliar place are faced with the acquisition of a new language and culture. Perhaps most importantly, Hoffman shows us that the transformation can be slow, painful, and complex - a process that requires a seemingly endless number of adjustments. When that process is finally complete (if it is, in fact, ever complete), there is significant variation in the types of bicultural identities developed by different individuals, since identity formation is inevitably influenced by unique personal and social factors. Research shows, however, that the process of becoming bicultural is not free of certain commonalities. In this section, I look at the theoretical approaches to biculturalism, paying particular attention to the factors that influence its development, the different types of bicultural identities developed by immigrants, and the possible benefits and drawbacks of biculturalism for both the individual and society.

\section{The marginal model}

According to a number of researchers (LaFromboise, Coleman, \& Gerton, 1993; Padillla, 2006; Marino Weisman, 2001), the concept of bicultural identity was first explored by Park (1928), who referred to those who have internalized two cultures as 
'marginal' people with 'dual-culture membership' (LaFromboise et al., 1993; Padilla, 2006). Park's work, however, comes from a different era of sociology and is largely theoretical and at times simply anecdotal. It is not based on any empirical research but rather on the works of other sociologists, most notably Simmel's (1908) Sociologie, and memoirs of immigrant writers, such as Lewisohns' (1922) Up Stream.

Today, researchers consider it to be an outdated model not only because it was conceived in the 1920s, but because Park (1928) makes assumptions that have since been questioned by empirical research. LaFromboise et al. (1993) and Padilla (2006), for example, claim that the marginal man model is outdated because it describes dual-culture membership as difficult and psychologically demanding: "The common assumption, exemplified by the position of Park (1928) [...], is that living in two cultures is psychologically undesirable because managing the complexity of dual reference points generates ambiguity, identity confusion, and normlessness" (LaFromboise et al., 1993, p. 395). Padilla goes even further in his criticism of Park: "[T] he marginal person feels isolated and closed off from members of either the culture of origin or the culture of the host group or, worse, isolated from both [...] the person suffers from self-hatred, low selfesteem, and feelings of inferiority [and] is marked by negativity and character traits that predispose the individual to serious mental health problems" (Padilla, 2006, p. 470).

A closer look at Park (1928) shows, however, that the above criticisms are at least partially unfounded. For Park, migration is a catalyst for social and cultural change, with the migrants embodying that change within themselves. Though Park states that biculturalism is likely psychologically uncomfortable, he acknowledges the possible benefits of dual-culture membership as an emancipating force. "[The individuals] 
become, in the process, not merely emancipated, but enlightened. The emancipated individual becomes [...] to a certain degree a cosmopolitan. He learns to look upon the world in which he was born and bred with something of the detachment of a stranger" (Park, 1928, p. 888). What Park says here does not resemble Padilla's (2006) claims that the marginal individual "suffers from self-hatred". In fact, it could be argued that Park celebrates the cultural detachment and objectivity experienced by biculturals. However, it is unclear how Park, a monocultural himself, arrived at these very general conclusions.

The idea of detachment is also prevalent in Hoffman's memoir. For Hoffman (1989), this detachment is a result of a constant triangulation - an awareness of a third point of reference:

A voice, almost unconscious, keeps performing an inaudible, perpetual triangulation [...]. I am here, feeling the currents of conflict and warmth, but from that other point in the triangle, this is just one arbitrary version of reality. [...] [T] he other place in my mind no longer has any particularity. It's just an awareness that there is another place [...], which renders this place relative, which locates me within that relativity itself. (p. 170)

Hoffman uses detachment as a powerful intellectual tool that allows her to remain both inside and outside of the context, and, arguably, helps her become a perceptive observer of North American life.

In a qualitative study of immigrant women, De Korne, Byram, and Fleming (2007) found that this detachment is a major component of the bicultural experience. Here, as in Hoffman, the detachment comes from having multiple reference points and belonging "to both and neither culture entirely" (De Korne et al., 2007, p. 296). For De 
Korne et al.'s participants, this is desirable. They report that their experiences as outsiders have made them more open-minded and adaptable and have helped them develop an ability to successfully interact with members of different cultures. The participants also claim that they are more critical of both their culture of residence and culture of origin than monocultural individuals. In other words, they have become members of a new culture while retaining the perspective of their original culture - as they view their new (or old) world they are able to employ multiple points of view and remain objective and critical (De Korne et al., 2007).

There seems, therefore, to be recent support for some of the claims made by Park more than eighty years ago. But what about some of the other aspects of the marginal model? Park (1928) highlights the variability of 'marginal' personalities and how their development might be affected by social circumstances (racism), the characteristics of the minority group (visible minority or not), and the personal traits of individual immigrants. The variability caused by these factors is explored in-depth in biculturalism and acculturation research, with findings generally supporting Park's claims. The research shows that, when minority groups are not viewed favourably by the dominant population, the cultural acquisition process is negatively influenced (Berry, 1984, 2005; LaFromboise et al., 1993; Phinney, 1989, 2001; Tartakovsky, 2009). These studies will be explored in more detail later, in a section dealing with acculturation literature.

Park (1928) also claims that the struggle between the different identities is most prevalent during the period of transition when "old habits are being discarded and new ones have not yet formed" (Park, 1928, p. 893). While this struggle is documented in some recent works (Hoffman, 1989; Zajacova, 2001, Tartakovsky, 2009), it is arguably 
the idea of discarding 'old habits', coupled with the 'relatively permanent period of crisis' allegedly experienced by immigrants, that suggests that Park's framework is outdated. Discarding old habits implies that assimilation is the most desirable outcome for both the immigrant and the society; today, there is a wide consensus that integration, which emphasizes the maintenance of the original culture, is a better model (Berry, 1997; Phinney, 1990, 2001). The assumption that immigrants struggle with their double identities eternally, and that this struggle is necessarily a crisis, is not consistent with contemporary thought (David, 2009; Hoffman, 1989; De Korne et al., 2007;

LaFromboise et al., 1993).

\section{The biculturalist approach}

The marginal model has only recently been replaced with a biculturalist/multiculturalist approach that celebrates membership in multiple cultures (Padilla, 2006). Padilla suggests that "[a]ccording to this more contemporary view, it is possible to be a competent member of two cultures without being in serious psychological conflict about either" (p. 470). The modern marginal individual enjoys all the benefits outlined by Park (1928), without the unfortunate and permanent identity crisis.

The contemporary view of biculturalism is carefully elaborated in the often-cited paper, Psychological impact of biculturalism: evidence and theory, in which LaFromboise et al. (1993) present a detailed review of literature on second-culture acquisition and produce a comprehensive theoretical framework of biculturalism. They begin by reviewing the five major models of second-culture acquisition: assimilation, acculturation, alternation, multicultural, and fusion. Of these, they argue, the model of 
alternation is best suited for the acquisition of additional cultures; the other models are problematic for a number of reasons.

Both the assimilation and acculturation models assume that cultural acquisition proceeds linearly as individuals gradually discard their culture of origin in favour of the culture of the majority. Both models are based on a cultural hierarchy where the majority culture is given more importance than the culture of origin. These models are often associated with significant psychological stress. Under the assimilation model, the stress is most prevalent during the time of transition, when immigrants may be breaking away from members of the original culture but are not yet accepted by the majority. There is also the risk of never being accepted by the majority and, consequently, becoming isolated from both groups. The acculturating immigrants, on the other hand, are never allowed to assimilate and, therefore, continue to be identified as a minority group. As a result, they are unable to shed their original culture and, though they may become competent participants in the majority culture, they are never allowed to become equal members (LaFromboise et al., 1993).

"The alternation model of second-culture acquisition assumes that it is possible for an individual to know and understand two different cultures. It also supposes that an individual can alter his or her behaviour to fit a particular context" (LaFromboise et al., 1993, p. 399). Proponents of this model view cultural acquisition as additive, bidirectional, and flexible. The bicultural individual is equally comfortable within the minority and majority culture, assigns them equal status, and is able to select and internalize the best aspects of each world. 
After considering the alternation model, LaFromboise et al. (1993) discuss the multicultural model. The only difference between the alternation and the multicultural models is that the alternation model does not necessarily require a pluralistic, multicultural social structure for biculturalism to flourish. The multicultural model depends, perhaps too much, on an idealized, utopian vision of a multicultural society that "encourages all groups to (a) maintain and develop their group identities, (b) develop other-group acceptance and tolerance, (c) engage in intergroup contact and sharing, and (d) learn each other's language" (LaFromboise et al., 1993, p. 401). While the multicultural model is arguably too context-dependent, it is not clear what role, if any, the context plays in the alternation model. LaFromboise et al. seem to claim that cultural acquisition is an exclusively individual endeavour that is not influenced by such social factors as, for example, the majority's attitudes toward the minority. One might argue that the alternation approach is too individualistic, too devoid of context, and therefore too idealized.

The last model of cultural acquisition considered by LaFromboise et al. (1993) is the fusion model. It is important to note that, in this model, unlike in the other four examined by LaFromboise et al., cultural acquisition is considered from a social, not an individual, perspective. The model focuses primarily on what happens to social groups (minority and majority) during migration, and only as an afterthought looks at how individuals might be affected by cultural contact. It suggests that minority and majority cultures will, as the name implies, fuse to form a new culture. As LaFromboise et al. point out, this is the assumption behind the melting pot theory. Though in theory this model differs from assimilation because there is a lack of cultural hierarchy and an 
assumption that both the majority and minority cultures undergo a transformation, in reality there is little known about how the majority is affected by interaction with minorities. It seems that, during the fusing, minority members are expected to replace their culture with that of the majority, making this model quite similar to assimilation (LaFromboise et al. 1993).

Of the models considered, LaFromboise et al. (1993) argue that the alternation model is best suited for the acquisition of an additional culture. It should be noted that the alternation model is also known as the two-dimensional model of cultural acquisition (particularly in acculturation research), currently the widely accepted alternative to the more traditional bipolar model. The bipolar model assumes that the culture of origin and the culture of the majority occupy the opposite points of a continuum, and that these identities are "contradictory and one comes at the expense of the other" (Tartakovsky, 2009 , p. 656). Therefore, cultural acquisition is seen as a movement along the continuum where immigrants can successfully 'integrate' only if they 'discard' and 'replace' their culture of origin with the new culture. According to this model, any attempts "to affiliate simultaneously with two cultural groups leads to the creation of an incongruous and unstable sense of self and to less than optimal psychological functioning" (Tartakovsky, 2009, p. 656).

The two-dimensional model, on the other hand, assumes that cultural identities exist independently, and that both play an important role in immigrants' adjustment to a new environment. Proponents of this model argue that "the integration of the two cultures within an individual is not only possible but also desirable [...]" (Tartakovsky, 2009, p. 656). This is consistent with the modern biculturalist/multiculturalist approach. It is 
important to note, however, that empirical research has not unequivocally confirmed the accuracy of either model, and that much variability exists in immigrants' adjustment to new cultures (Tartakovsky, 2009).

LaFromboise et al. (1993) too acknowledge that the models of second culture acquisition are not mutually exclusive and that immigrants' cultural acquisition may differ greatly depending on personal and social circumstances. They do, however, believe that the alternation model is best-suited for a 'healthy' biculturalism and base their construct of bicultural competence on its assumptions: that cultural acquisition is additive, that bicultural individuals can be equally comfortable existing in two cultures, that they can freely alternate between cultures depending on the context, and that they have the ability to integrate the 'best' qualities of both cultures. In order to attain this cultural flexibility, the individual must develop bicultural competence (BCC), which is composed of six dimensions: (i) knowledge of cultural values and beliefs; (ii) positive attitude towards both majority and minority groups; (iii) bicultural efficacy; (iv) communication ability; (v) role repertoire; and (vi) groundedness.

\section{(i) Knowledge of cultural beliefs and values}

A competent bicultural will have a good understanding of both the culture of origin and the new culture. "This would include an understanding of the basic perspectives a culture has on gender roles, religious practices, and political issues, as well as the rules that govern daily interactions among members of the culture" (LaFromboise et al., 1993, p. 403). Further, the individual should appreciate and internalize the worldviews and beliefs of each culture and be able to act within the boundaries of each, depending on the context. 
A study by Hong, Morris, Chiu, and Benet-Martínez (2000) confirms this notion by showing that bicultural individuals engage in cultural frame switching when primed with different cultural cues. Their participants, who were Hong Kong biculturals, were placed into one of three experimental groups: the American culture condition, the Chinese culture condition, or the control condition. The cultural primes used included symbols, legendary figures or popular cartoons, famous people, and landmarks. After seeing the primes, participants were asked to write a series of sentences describing the icons in relation to American/Chinese culture, or answer a series of questions. During the final task, participants were either asked to interpret a series of images (e.g. a fish swimming ahead of a group of fish), or interpret a short story. The participants primed with American icons consistently assigned internal attributions (identified as American) to images and stories, while those primed with Chinese icons assigned external attributions (identified as Chinese) to the same images and stories. The experiments were repeated with a group of Chinese-Americans and showed similar results (Hong et al., 2000). The studies showed that biculturals alternated between typically Western and Chinese behaviours depending on cultural primes. "This work suggests that culture is not monolithic: People have access to multiple cultural meaning systems and switch between different culturally appropriate behaviors depending on the context" (Benet-Martínez, Leu, Lee, \& Morris, 2002, p. 493). Later studies further confirm the occurrence of frame switching among biculturals (Luna, Ringberg, \& Peracchio, 2008; Mok \& Morris, 2009). LaFromboise et al. (1993) admit that the internalization of two cultures might be problematic when there is a significant discrepancy between the belief systems of the two cultures. They point out that "[i]f the values and beliefs of the two cultures are in 
conflict, the individual may internalize that conflict in an attempt to find an integrated resolution [...]" (LaFromboise et al., 1993, p. 403). Though the authors acknowledge the complexity and possible negative effects of this phenomenon, they offer no solutions and call for more research in the area.

Benet-Martínez et al. (2002) are among the few researchers who have attempted to address the issue with the development of their bicultural identity integration (BII) construct. BII complements the work of Hong et al. (2000) on cultural frame switching; it attempts to describe the variability in individuals' frame-switching behaviour and integration of multiple cultures. "[A]lthough all biculturals identify with both mainstream and ethnic cultures, some biculturals perceive their dual cultural identities as compatible and integrated, whereas others see them as oppositional and difficult to integrate" (BenetMartínez et al., 2002, p. 496). In a quantitative study of Chinese Americans BII was measured using a short biographical questionnaire (e.g. age, length of residence in US/China, language proficiency, cultural identification) and a vignette adopted from Phinney \& Devich-Navarro (1997) composed of "key statements that best differentiate low BIIs from high BIIs" (Benet-Martínez et al., 2002, p. 498). The vignette read, "I am a bicultural who keeps American and Chinese cultures separate and feels conflicted about these two cultures. I am simply a Chinese who lives in America (vs. a ChineseAmerican), and I feel as someone who is caught between two cultures" (Benet-Martínez et al., 2002, p. 498). Individuals who responded closer to 1 (definitely not true) were labeled as high BIIs - they have an integrated bicultural identity and see themselves as part of a combined or hyphenated culture (Chinese-American), and view their two cultures as largely compatible. Those with low BII (scoring closer to 8 - definitely true) 
have internalized the incompatibility of their two cultures and feel as though they are moving between the two cultures (Miramontez, Benet-Martínez, \& Nguyen, 2008). Comparing BII scores with questionnaire data suggested that "compared to those with high BII, low BII individuals were less assimilated into American culture and more involved in Chinese culture" (Benet-Martínez et al., 2002, p. 503).

Finally, the researchers replicated the experiment of Hong et al. (2000), showing that high BIIs were more likely to respond positively to cultural priming (i.e. assign attributes of the primed culture to the final task). On the other hand, low BIIs responded to cultural priming in an inverse manner (e.g. assigning Chinese attributes to the final task after being primed with American icons) (Benet-Martínez et al., 2002). BenetMartínez et al., drawing on examples from "popular media and literature," argue that the latter reflects the experiences of biculturals who act (or feel) in opposition to the cultural context in which they find themselves. An example of this would be a Polish-Canadian feeling more Polish when in Canada than when in Poland. While this argument is an interesting one, the authors offer no empirical evidence that only low BIIs experience this phenomenon. They fail to establish a link between oppositional frame switching and behaviour within specific socio-cultural contexts. The work by Hong et al. (2000) and Benet-Martínez et al. (2002) does, however, lend empirical support to the first dimension of BCC.

(ii) Positive attitude toward both majority and minority groups

The second dimension of BCC - positive attitude towards both groups - is key in facilitating bicultural competence. LaFromboise et al. (1993) acknowledge that this attitude is, to a great degree, determined by the type of interaction that exists between the 
groups within a particular context. If that interaction is marked by discrimination by the majority group, it will be more difficult for the minority members to develop a positive attitude towards the majority, and may also cause the minority group to have a negative perception of their culture of origin. LaFromboise et al. (1993) offer no solutions for this potentially serious problem. Instead, they argue that cultural translators, those who have successfully socialized into both groups, can assist in helping minority members better understand majority culture. It is, therefore, the responsibility of the individual to 'properly' socialize into both worlds, though the authors admit that positive interaction and cultural understanding are beneficial to both minority and majority members.

The effects of group interaction on bicultural development are looked at in greater detail by researchers dealing with acculturation. There are numerous studies of acculturation and ethnic/national identity that deal with in-group/out-group attitudes and their effect on members of immigrant groups (Berry, 1984, 2005; Phinney, 1990, 1997, 2001; Tartakovsky, 2009) These often draw on Tajfel and Turner's (1986) work on social identity theory (SIT). Both acculturation research and SIT will be looked at in more detail later.

\section{(iii) Bicultural efficacy}

LaFromboise et al. (1993) define bicultural efficacy as "the belief, or confidence, that one can live effectively, and in a satisfying manner, within two groups without compromising one's sense of cultural identity" (LaFromboise et al., 1993, p. 404). The higher the level of bicultural efficacy, the more likely the individual is to develop a healthy bicultural identity. This dimension is seen as the main motivator behind bicultural competence. Though self-efficacy is a widely studied phenomenon in psychology, bicultural efficacy 
has not been discussed by other researchers (with the exception of David, Ozaki, and Saw (2009), a study discussed in more detail below).

\section{(iv) Communication ability}

The ability to communicate effectively in the minority and majority language is obviously a key element of bicultural competence. For some groups and individuals it may be, in fact, the most important aspect of being a successful bicultural. ${ }^{2}$ of importance here, therefore, is not only the acquisition of the new language, but also the retention of the original language as both languages are instrumental in maintaining a link to their respective cultures. LaFromboise et al. (1993) review a number of studies that look at language and biculturalism. The findings of these studies suggest that (1) bilingual education that emphasizes maintenance of the first language may "promote bicultural competence rather than assimilation" and have positive psychological effects (LaFromboise et al., 1993, p. 405), (2) immigrants' attitudes toward their own group and toward the majority may be related to language proficiency where those with a positive attitude to both groups show the highest proficiency in (or interest in learning/maintaining) both languages, (3) "speech norms are used to identify in-group and out-group members" and that non-standard usage can result in discrimination by the majority, (4) more acculturated immigrants tend to speak English at home, and finally, (5) for some groups, increased proficiency in the second language resulted in improved economic conditions but also first language loss.

\footnotetext{
2 But biculturals need not necessarily be bilingual, do they? How does this relate to, for example, an Australian moving to Canada and sharing the language, but not the culture of the majority?
} 
LaFromboise et al.'s (1993) review of the literature on language and biculturalism is fairly comprehensive, but it is, arguably, too broad and shallow. Each of the points noted above is illustrated by a single study, each carried-out with very different groups of biculturals (ranging from aboriginal Canadians to Mexican Americans). It is, therefore, not clear whether the arguments made above are relevant beyond each group studied. What the review does suggest, however (though this is never stated explicitly by LaFromboise et al.), is that the link between language and identity may vary greatly across groups and individuals.

Though LaFromboise et al. (1993), as well as other researchers dealing with biculturalism and immigrant integration, pay some attention to language and its link to culture and identity, this link is not as firmly established as it should be. This potential shortcoming of research on biculturalism will be examined in greater detail during the discussion of language and identity later in the paper.

\section{(v) Role repertoire}

As LaFromboise et al. (1993) explain, "role repertoire refers to the range of culturally or situationally appropriate behaviours or roles an individual has developed. The greater the range of behaviours or roles, the higher the level of cultural competence" (p. 406). This aspect of bicultural competence is clearly dependent on the individual's knowledge of cultural beliefs and values and an ability to communicate in both languages. It is unclear why role repertoire is treated as a unique dimension by the researchers. There appears to be no research that deals with this dimension as a unique aspect of biculturalism. 


\section{(vi) Groundedness}

In order to be biculturally competent, individuals should maintain social support networks in their culture of origin and develop new networks in the host society. Involvement with members of the home culture is important at the beginning of immigration as it helps to relieve some of the stress associated with culture shock. Later, these networks are necessary to help retain the original language and culture. At the same time, membership in majority social networks is necessary in order to develop an understanding of the majority group (LaFromboise et al., 1993).

LaFromboise et al. (1993) do not go beyond the simple (and rather obvious) conclusion that successful biculturals, through participation in social networks, remain grounded in both cultures. While this may be true, it is important to note that the development of social networks in both cultures is related to a number of complex psychological and social factors. Mok, Morris, Benet-Martínez, and KarakitapogluAygün (2007) attempt to link BII with social network characteristics of first-generation Chinese-American immigrants. They argue that "immigrants who accept the host culture into their subjective identities accept the host culture into their social networks" (Mok et al., 2007, p. 629). Their study of 111 Chinese-Americans shows that there is a correlation between BII and social network structure and density. More specifically, individuals with high BIIs were more likely to have mixed networks of Chinese and non-Chinese friends.

Wei, Milroy, and Shing (2007) examine immigrant social networks from a sociolinguistic perspective, trying to establish the connection between social networks and language choice in bilingual biculturals. The networks are classified in terms of weak and strong ties and fall under one of three types: exchange networks, interactive 
networks, and passive networks. Exchange networks are composed of close family and friends with whom the individual has frequent contact and "exchanges direct aid, advice, criticism and support" (Wei et al., 2007, p. 141). Interactive networks are characterized by frequent contact but are not relied on for more personal needs. Interactive networks may be composed of colleagues and other casual acquaintances. Passive networks, like interactive networks, are composed of individuals who may be valued "as a source of influence and moral support," (p. 141) but with whom interaction is infrequent. In case of the immigrants, members of these networks may include family members and friends left behind in the country of origin ${ }^{3}$.

Wei et al. (2007) examine the language choice and social networks of 59 firstand second-generation Chinese speakers (in 10 families) in England. Their findings are not unexpected: Chinese immigrants with social networks composed mostly of other Chinese speakers tend to use more Chinese; Chinese speakers with social networks composed of more non-Chinese speaking members, tend to use more English. Not surprisingly, second-generation immigrants tend to use English much more often than their parents. The study, however, shows more variability for the connection between language choice and variables such as age, gender, etc. Wei et al. (2007) show that the connection between social network membership and language use is much more predictive.

Perhaps more interesting (at least for the purpose of this thesis) are the factors that determine an individual's choice of networks. Is language use the reason why people

\footnotetext{
${ }^{3}$ It is important to note, however, that, at least in the case of immigrants, the distinction between exchange and passive networks has become blurred in recent years. This is mostly due to the increased use of technologies such as email and Skype, which have rendered many passive ties more frequent (Lanza \& Svendsen, 2007).
} 
choose a particular network, or is it an outcome of being 'forced' into specific networks by external factors (or both)? As Wei et al. (2007) point out, “[a]s well as relating interactional and community levels of analysis, network structure can relate to social, economic and political structure. $[\ldots][$ T] he various network types $[\ldots]$ do not constitute themselves in a socially arbitrary fashion" (p. 155). In the case of the Chinese immigrants considered in the above study, the networks were constructed in relation to various social and economic realities, as well as Chinese cultural traits (e.g. Many of the first generation immigrants were employed in Chinese businesses; kin-oriented networks, a trait associated with Chinese culture, were common). The studies mentioned above show that the concept of groundedness is far more complex than LaFromboise et al. (1993) would have us believe - while, in theory, being grounded in dual networks may be desirable (and a reflection of a 'healthy/true' biculturalism), in practice, becoming a member of dual networks is likely a complex and difficult task.

Even with its occasional oversimplifications, $\mathrm{BCC}$ seems to be the most comprehensive model of biculturalism available. Despite this, there is only one empirical study that tested LaFromboise et al.'s (1993) bicultural competence as an integrated construct and considered all six dimensions of BCC in relation to biculturalism. David et al. (2009) conducted a quantitative study of perceived self-efficacy of bicultural individuals. They developed the Bicultural Self-Efficacy Scale, which reflected the six dimensions of BCC and found "that perceived bicultural self-efficacy [was] better conceptualized and assessed as composing six related factors, providing empirical support to bicultural competence theory"(David et al, 2009, p. 222). They further found that participants who were biculturally competent (according to the six dimensions of 
LaFromboise et al.) scored high on the bicultural self-efficacy scale, and that this had positive psychological effects. In other words, "the belief in one's ability to function in two cultures may lead to better life satisfaction and lower levels of anxiety and depression symptoms among bicultural individuals" (David et al., 2009, p. 223).

The lack of interest in testing BCC as a unified construct is somewhat surprising considering that the article by LaFromboise et al. (1993) is often cited by writers dealing with biculturalism. This may be due to some inherent problems with BCC, though there does not appear to be any criticism of it in the literature on biculturalism. Perhaps this lack of interest is a reflection of a more general apathy towards the study of biculturalism and bicultural identity, a field that has received relatively little attention from scholars (De Korne et al., 2007). This 'neglect' is discussed by Benet-Martínez and Haritatos (2005), who conducted an extensive survey of the psychological literature on biculturalism and multiculturalism and found only 28 empirical studies published between 1953 and the time of the survey. "Given the size of the identity literature (> 1000 papers), these low numbers indicate a huge knowledge gap in the understanding of bicultural identity formation and maintenance, and cultural identity in general" (BenetMartínez \& Haritatos, 2005, p. 1016).

\section{Biculturalism in Acculturation Research}

In fact, biculturalism has traditionally been explored as an aspect, or the potential outcome, of acculturation, especially in the works of Berry $(1980,1984,2005)$ and Phinney and colleagues (Phinney, 1990, 1992; Phinney, Cantu, \& Kurtz, 1997; Phinney \& Devich-Navarro, 1997; Phinney \& Ong, 2007). Both authors work within the framework of the two-dimensional model of cultural acquisition mentioned during the 
discussion of LaFromboise et al.'s (1993) model of alternation. As such, both Berry and Phinney view cultural acquisition as non-linear and advocate the maintenance of the culture of origin during the acquisition of a new culture.

For Berry $(1980,1984,2005)$, the acquisition of a new culture, or, more specifically, the changes that occur in extended cross-cultural contact, happen at two different but inevitably interconnected levels: the cultural/group level, and the psychological/individual level (Berry, 2005). The cultural level is composed of five aspects: "the two original cultures (A and B), the two changing cultures (A1 and B1), and the nature of their contact and interactions. These five sets of phenomena define the nature of the acculturation process at the cultural level and establish the starting point for the process of acculturation at the psychological level" (2005, p. 702). Berry argues that an examination of psychological/individual acculturation should begin with a detailed analysis of the five aspects of cultural acculturation.

Psychological acculturation is composed of four strategies that individuals may 'choose' to adopt when faced with the acquisition of a new culture. These are integration, assimilation, separation, and marginalization (Berry, 1980), all based on the "distinction between (1) a relative preference for maintaining one's heritage culture and identity, and (2) a relative preference for having contact with and participating in the larger society [...]" (Berry, 2005, p. 704). Integrated individuals maintain their heritage while interacting with other groups. Assimilated individuals show a loss of culture of origin in favour of the new culture. Separated individuals maintain relationships with members of their ethnic group and avoid contact with other groups. Finally, marginalized individuals do not interact with members of either culture (Berry, 2005). 
In a large multinational study of immigrant youth ( $\mathrm{N}=5298)$, Phinney, Berry, Vedder and Liebkind (2006) tested the validity of the acculturation construct. They posed three questions: (1) How do people acculturate? (2) How well do people adapt? (3) What is the relationship between how they acculturate and how they adapt? Phinney et al. (2006) found that acculturation falls into the four distinct strategies predicted by the acculturation model. They also found that integration was the preferred method of acculturation amongst immigrants and it resulted in the best psychological adaptation. Participants in this group "had positive national and ethnic identities, used both heritage and national languages, and had friends from both groups" (Phinney et al. 2006, p. 115).

Berry's integrated individual is much like LaFromboise et al.'s (1993) competent bicultural - a person who is a capable participant in multiple cultures. Berry also realizes that, though immigrants may prefer an integration strategy, this is often limited by the attitude of the dominant group. "[I]ntegration can only be 'freely' chosen and successfully pursued by non-dominant groups when the dominant society is open and inclusive in its orientation towards cultural diversity" (Berry, 2005, p. 706). Of course, Berry acknowledges that integration is a dual process in which both cultural groups play a role. "This strategy requires non-dominant groups to adopt the basic values of the larger society, while at the same time the dominant group must be prepared to adapt national institutions $[\ldots]$ to better meet the needs of all groups now living together in a plural society" (Berry, 2005, p. 705). Though Berry recognizes that immigrant adaptation depends on many external factors, he seems to claim that particular strategies are 'chosen' by individuals. The extent to which people consciously choose acculturation strategies, however, is questionable. Berry's work is concerned with the outcomes of 
acculturation (measured at a particular moment in time), not the dynamics of the process, and, therefore, says little about how acculturating individuals adopt a particular strategy. 'Choosing' also implies that individual choice, though perhaps somewhat limited by context, is the driving force behind acculturation, but it is not clear whether that is, in fact, the case.

The interplay between the context and immigrant adaptation is also discussed by Phinney, Horenczyk, Liebkind, and Vedder (2001), who argue that "[t]hese complex processes can best be understood in terms of an interactional model that takes into account the culture, identity attitudes, and preferences of the immigrants, the characteristics of the place of settlement, and the interaction among these factors" (p. 505). Their review of the empirical research on immigrant acculturation across several countries shows that, although the integration strategy seems to result in the highest psychological well-being, it is by no means found most often. The acculturation strategy adopted, as already mentioned, depends on a number of complex factors unique to each group and setting and therefore shows great variability (Phinney et al., 2001).

As stated at the outset of this section, both Phinney and Berry work within the paradigm of two-dimensional (non-linear) cultural acquisition. Phinney's research complements Berry's work on acculturation but looks more specifically at the interaction between, and development of, individuals' ethnic and national identities, where ethnic identity refers to the identity of culture of origin, and national identity refers to the identity of the new (receiving) culture (see Phinney, 1990, 1992; Phinney, et al. 1997; Phinney \& Devich-Navarro, 1997; Phinney \& Ong, 2007). As proposed by the two- 
dimensional model of cultural acquisition, these identities are independent; in other words, one does not exist at the cost of the other, does not replace it.

Phinney's research supports Berry's findings that an integrated (bicultural) identity, "that is, the combination of strong ethnic and national identities, promotes the most healthy psychological adaptation, whereas low scores on these two identities are related to poor adaptation" (Phinney et al., 2001, p. 502) (see also Phinney et al., 1997; Phinney \& Devich-Navarro, 1997; Phinney \& Ong, 2007). But what exactly does this mean? More specifically, what are ethnic and national identities and how are they measured?

In a review of research on the matter, Phinney (1990) admits that there is a lack of consensus on what ethnic identity means. "The fact that there is no widely agreed-on definition of ethnic identity is indicative of confusion about the topic" (p. 500). Despite the seeming lack of consensus, Phinney is able to compile a list of components examined by ethnic identity researchers. These fall into two categories: components that describe individuals" state of ethnic identity at a particular moment in time - "self-identification as a group member, a sense of belonging to the group, attitudes about one's group membership, and ethnic involvement (social participation, cultural practices and attitudes)" (p. 503); and, in a small portion of the studies, researchers examine the dynamic process of identity formation over time (Phinney, 1990).

Self-identification as a group member is an important starting point in examining participants' ethnic identity (Phinney, 1990). When looking at immigrants, selfidentification can tell us whether individuals identify with both ethnic and national cultures (e.g. By using hyphenated labels such as Mexican-American). In other words, 
self-identification gives an initial indication of whether the participants have, in Berry's words, an integrated, assimilated, separated, or marginalized identity.

Sense of belonging to a group can be assessed by considering self-identification combined with responses to a variety of relevant statements (e.g. I feel a strong bond towards people of my ethnic group) (Phinney, 1990). Positive and negative attitudes toward one's ethnic group are also a key aspect of ethnic identity. Being proud of the cultural practices and the achievements of one's ethnic group indicates a positive attitude toward one's group; "displeasure, dissatisfaction, discontent with one's ethnicity; feelings of inferiority; or a desire to hide one's cultural identity" are examples of negative attitudes toward one's ethnic group (Phinney, 1990, p. 505).

Ethnic involvement (social participation and cultural practices) is "the most widely used indicator of ethnic identity [...]" (p. 505). This component is assessed based on an examination of language use, friendship networks, religious affiliation and practice, participation in structured ethnic social groups, political ideology and activity, and miscellaneous ethnic/cultural activities and attitudes (Phinney, 1990). According to Phinney, ethnic involvement is a group-specific component of ethnic identity and, as such, is later excluded from her non-group specific measure of ethnic identity.

Phinney argues that, of the commonly examined components of ethnic identity, self-identification, sense of belonging, pride in one's group, and ethnic identity development seem to be non-group specific. These can therefore be used as the basis for creating a measure of ethnic identity that will be generalizable to all ethnic groups. She notes that "in the theories and definitions presented by researchers, ethnic identity was treated as a general phenomenon that is relevant across groups. Yet researchers have 
attempted to answer theoretical and definitional questions almost exclusively in terms of one group or, sometimes, a few specific groups" (Phinney, 1990, p. 507). Therefore, in order to create a 'universal' construct of ethnic identity, the context/group-specific component, ethnic involvement, should be excluded.

Phinney (1992) follows this rationale in developing the Multigroup Measure of Ethnic Identity (MEIM). MEIM consists of 14 items that measure three components of ethnic identity: positive ethnic attitude and sense of belonging, ethnic identity achievement, and ethnic behaviours and practices. Each item is a statement the response to which is measured on a four-point scale from strongly agree to strongly disagree. Ethnic attitude and sense of belonging are assessed based on five items (e.g. I have a lot of pride in my ethnic group and its accomplishments). Ethnic identity achievement, "including both exploration and resolution of identity issues" is represented by seven items (e.g. I have spent time trying to find out more about my own ethnic group, such as history, traditions, and customs) (Phinney, 1992, p. 164). Finally, ethnic behaviours and practices are measured by two items (e.g. I am active in organizations or social groups that include most members of my own ethnic group) (Phinney, 1992).

Notably missing from MEIM is an exploration of language as a component of ethnic identity. This is not an accidental omission: "Language usage, another widely used indicator of ethnic identity, has different salience with various groups (and virtually none for some) and thus cannot be included in a general measure" (Phinney, 1992, p. 159). Phinney adds that language usage, along with group-specific practices and traditions, can be explored in detailed studies of particular groups, but not in a general construct which aims to compare different groups. This said, MEIM has been used to assess ethnic 
identity in several studies that deal with specific immigrant groups, without looking specifically at language use or other aspects of ethnic involvement (Umana-Taylor \& Fine, 2001; Cachelin, Phinney, Shug, \& Striegel-More, 2006; Dandy, Durkin, McEvoy, Barber, \& Houghton, 2008). The omission of language in studies of immigrants (for whom language use is certainly an important characteristic) is troubling, showing that MEIM is, at least in some studies, not used along with other measures of identity, likely giving an incomplete depiction of ethnic identity.

It must also be noted that, while Phinney pays considerable attention to developing an 'accurate' assessment of ethnic identity, her measurement of national identity is much simpler. In a study of ethnically diverse adolescents it "was assessed with a single item that asked, 'How strongly do you think of yourself as American?' Responses were on a 4-point scale from (4) Very strongly to (1) Very weakly" (Phinney, Cantu, \& Kurtz, 1996). The discrepancy between the tools used to measure the two identities is striking. Surely, national identity is more complex than simply thinking of oneself as American (a term that, in itself, lacks definition). Also, how can a claim that someone feels strongly American be verified and trusted without other questionnaire items that elicit the what and how of national identity (e.g. sense of belonging, pride, cultural practices, etc.)?

This oversimplification of national identity is problematic because key to Phinney's examination of minority groups is the interplay between the two identities and how they form the resulting cultural identity, which "focuses on the immigrants" sense of self rather than on their behaviours and attitudes following immigration" (Phinney et al. 2006, p. 71). While the discrepancy between the treatment of the two identities is clearly 
problematic (and will be discussed in more detail later), it is important to consider what Phinney and colleagues mean by 'sense of self'.

Their definition of cultural identity revolves around an individual's "sense of belonging to one or more cultural groups and the feelings associated with group membership" (Phinney et al., 2006, p. 76). Phinney et al. admit that this definition of cultural identity is closely linked to Tajfel and Turner's (1986) definition of social identity, which they define as the "aspects of an individual's self-image that derive from the social categories to which he perceives himself belonging" (p. 16). Social identity theory is based on a number of assumptions. One of these is that social behaviour falls somewhere on a continuum between two extremes - interpersonal and intergroup. Interpersonal behaviour is "fully determined by [individuals"] interpersonal relationships and individual characteristics, and not at all affected by various social categories to which they respectively belong" (e.g. interaction is entirely shaped by people's personality, as for example, the interaction between close friends) (Tajfel \& Turner, 1986, p. 8). Intergroup behaviour is completely determined by individuals' membership in social groups. For example, "the behaviour of soldiers from opposing armies during battle" (Tajfel \& Turner, 1986, p. 8)

Related to this is yet another continuum which describes "individuals' belief systems about the nature and the structure of the relations between social groups in their society" (Tajfel \& Turner, 1986, p. 9). At one end of the continuum, these beliefs are labeled as 'social mobility;' at the other, they are called 'social change.' Social mobility reflects a belief that the society is flexible and it is possible for individuals to move between groups. Social change describes a belief that the society is rigid and stratified 
and social movement is difficult, or even impossible. Tajfel and Turner (1986) argue that when individuals' beliefs reflect 'social mobility', their social behaviour is more likely to be interpersonal; conversely, if individuals' beliefs reflect the 'social change' belief, they are more likely to display intergroup behaviour (1986).

Framed within these continua, SIT operates based on three main assumptions: (1) That individuals try to achieve and maintain a positive self-image (sometimes referred to as self-concept); (2) Membership in social groups may be viewed as positive or negative depending on the status of the group - "[h]ence, social identity may be positive or negative according to the evaluations [...] of these groups that contribute to an individual's social identity" (Tajfel \& Turner, 1986, p. 16); and (3) Individuals evaluate their in-groups by making comparisons to out-groups. Tajfel and Turner (1986) outline three theoretical principals that stem from these assumptions: (1) "Individuals strive to achieve or maintain positive social identity" (p. 16); (2) Positive social identity results from favourable comparisons of individuals' in-groups with out-groups; and (3) If membership in a group results in a negative social identity, members will strive to leave the group, or, if that is not possible, create ways to redefine its group characteristics in order to make favourable comparisons with relevant out-groups (Tajfel \& Turner, 1986). Again, it must be noted that, while Phinney's (1992) measurement of ethnic identity (MEIM) reflects some of the aspects of SIT, her treatment of national identity in most subsequent studies remains poorly defined. This puts into question the reliability of some of her findings regarding the interplay of the two identities. However, there is at least one study conducted by Phinney that pays significantly more attention to national identity. 
In Phinney and Devich-Navarro (1997), national identity is assessed more carefully. The researchers use eight statements (e.g. I think of myself as being American; I am proud of being American) rated on a four-point scale. This quantitative component is used in conjunction with interview questions asking participants "about being American, such as how American they [feel], and what being American [means] to them" (Phinney \& Devich-Navarro, 1997, p. 14). This particular study is also worth examining for its treatment of biculturalism. It appears to be the only study Phinney conducted that deals specifically with biculturalism, drawing heavily on the work of LaFromboise et al. (1993).

The study looks at 52 African-American and 46 Mexican-American adolescents who were born in the United States. The researchers used a mixed method to measure participants' ethnic and national identities. They concluded that 90 percent of the participants could be described as bicultural, with their biculturalism falling into one of two categories: blended or alternating. The 10 percent that identified only with the ethnic culture were classified as separated, and were not considered bicultural. Blended biculturals had a strong sense of American (national) identity but also "retained a clear sense of their ethnicity" (Phinney \& Devich-Navarro, 1997, p. 25). The alternating biculturals identified strongly with their ethnic culture and, though "they acknowledged their American identity, $[\ldots]$ being American lacked a clear meaning for them, beyond the general idea of freedom" (p. 25). While the blended biculturals did, at times, feel pressure to be more 'ethnic', the alternating biculturals felt that, in certain contexts, they needed to adjust and act more 'mainstream.' The biggest difference between the two groups was that blended biculturals felt like they were part of a combined culture, while the 
alternating biculturals felt like they were moving between two cultures. Phinney and Devich-Navarro (1997) offer some interesting insight into one possible factor that might influence bicultural identity formation:

[T] he topic of American identity has not been widely studied, but it is clearly a key component of being bicultural. Although most of the adolescents acknowledged being American, they differed in the extent to which they felt included in the larger society. In fact, a determining factor in one's cultural identification appears to be the individual's perception of society; to feel bicultural, one must see the larger society as inclusive. For some adolescents, mostly the blended biculturals, America signified diversity; thus they could see themselves as part of it. [...] For other adolescents, especially the separated group, American meant white, and they were not part of it. (pp. 26-27)

Once again researchers stress the importance of context in bicultural identity formation. It is also interesting to note that Phinney and Devich-Navarro draw our attention to the importance of closely studying American (national) identity when looking at biculturalism, and they do a good job of accomplishing this feat in the above study with the use of both quantitative and qualitative data. It is surprising, therefore, that Phinney and her colleagues have since reverted back to treating national identity in a much simpler manner. For example, in a more recent study (Phinney et al., 2006), national identity is once again assessed using a very simple quantitative instrument that gives an oversimplified picture of national identity. This is probably partially due to the fact that most of the studies of acculturation conducted in social psychology are quantitative. The qualitative aspect of the above study is rarely found in the field but, arguably, provides a 
much richer picture of biculturalism. Nevertheless, this picture is, as the authors admit, still not quite complete: "[B]iculturalism is a complex and multidimensional phenomenon; there is not just one way of being bicultural. The patterns described, like any typologies, are oversimplifications; no doubt there is a range of possibilities for resolving the bicultural issue" (Phinney \& Devich-Navarro, 1997, p. 29). It is unfortunate, and somewhat surprising, that these researchers have not since conducted other mixed-method studies focusing specifically on biculturalism. This may again reflect the general lack of interest in biculturalism.

The treatment of biculturalism within the framework of acculturation has a number of shortcomings. One of these is that only the integrated individual is considered 'truly' bicultural. This argument is based on data that show integration as positively linked to psychological well-being. However, as shown by Benet-Martínez et al. (2002), individuals with conflicting cultural identities (low BIIs) are also bicultural. In fact, one might argue that most immigrants should be considered bicultural by virtue of living in a multicultural environment.

A more general critique of how acculturation researchers treat biculturalism states that these "models [...] focus on the outcome of acculturation more than on the process. Individuals are scored on the extent to which they have absorbed the new culture or retained the original one" (Hong et al., 2000, p. 718). But the process is an integral part of the bicultural experience and must, therefore, be given sufficient attention.

Also, the research presented in this section offers a fairly monolithic view of cultural identity, especially when discussing national identity (with the exception of Phinney \& Devich-Naverro, 1997). It is important to ask whether cultural identity can be 
reduced to a few questionnaire items. It could be argued that the intricacies of identity and culture cannot be effectively captured through quantitative methods alone, and that a qualitative approach might be more fitting to address this complex human experience. Unfortunately, the treatment of biculturalism within acculturation is mostly limited to quantitative studies.

Consequently, though acculturation research offers some valuable measures for the broad study of biculturalism, it fails to account for some key aspects of the bicultural experience. In addition to ignoring the process of becoming bicultural and oversimplifying cultural identity, researchers fail to address the more subtle aspects of the bicultural experience, such as detachment/triangulation (as discussed by Hoffman (1989) and De Korne et al. (2007)), the nature of interaction between the two identities and their manifestation in bicultural behaviour (as illustrated by Hong et al. (2000) and BenetMartínez et al. (2002)), and language use and its link to identity. Some of these gaps have already been addressed; the section below will address the last of these: the relationship between language use and bicultural immigrant identity.

\section{Language and identity}

It would be difficult to discuss the link between language and identity without considering the work of Fishman, one of the pioneers of the field. For Fishman (1989), there is a strong connection between language and culture. He acknowledges, however, that the relationship is complex: "[T] he whole truth about the relationship between language and culture will probably never be told. The relationship is both subtle and complex and has both objective and subjective dimensions" (Fishman, 1994, p. 84). 
Despite this complexity, Fishman $(1989,1994)$ proposes three dimensions that illustrate the ties between the two.

\section{(i) Language indexes culture}

The beliefs, values, and reality of a particular culture are always better expressed through its associated language rather than through another language. For example, languages have lexical items that reflect culturally-specific objects or abstractions; these items are often difficult (and sometimes impossible) to translate into another language creating semantic gaps (Fishman, 1994). Fishman states that "even the most accomplished and elaborate languages are suddenly inelegant, imprecise, unnatural and finally even ludicrous when put to the unfair task of expressing the nuances of a culture with which they have not been intimately identified" (Fishman, 1989, p. 470).

\section{(ii) Language symbolizes culture and its members}

Fishman argues that language is perhaps the most significant symbol of a particular culture and its people.

From our very earliest years and our most intimate socialization experiences we associate language with ourselves, with our loved ones, with relatives, friends, neighbours; in short 'with our kinds of people,' with our flag, with our country, with our cultural values and traditions and verities. This association is not always conscious, by any means, but it can be rendered conscious, and once this has been done the symbolic role of language achieves a political capacity and a potential thrust that is among the strongest motivators of collective human behaviour. (Fishman, 1994, p. 87) 
Fishman states that language, just like any symbol, stands for 'something'. In this case that 'something' is the group of speakers who use it. So, for example, German is associated with Germans, French with Frenchmen and so on. Fishman goes on to say that we may like the sounds of our own language but dislike the sounds of a language of those groups that we do not like, that we may want to learn the language of the people we like, and avoid learning (or forget) the language of those we do not. He says that both nationalist movements and language revival movements have drawn on the symbolic power of language and its link to ethnocultural identity.

\section{(iii) Culture is inherently linguistic}

The laws, tales, songs, greetings, and other cultural elements are expressed through language. Because of this, Fishman argues, a culture cannot be enacted without its associated language (1989). He admits that there are cultures that have survived despite language loss, but that these have been significantly altered during the process. Further, Fishman states that "no one can be a full-fledged, native (or even 'native-like') member of the culture and participate in [the] acts, events, occasions, and cultural processes without mastering the specific language in which they are implemented and lacking which they would not exist" $(1994$, p. 86). There is an emphasis here on both the instrumentality and symbolism of language.

A number of other linguists have argued for the link between language and identity. For Joseph $(2004,2006)$, identity has "two basic aspects: your name, which serves first of all to distinguish you from others (the deictic function), and then that deeper, intangible something that constitutes who you really are, which we might think of as the meaning of your name (the semantic function)" (Joseph, 2006, p. 486). It is that 
'deeper something' that Joseph is mostly concerned with in his work on language and identity. But it is no simple task to define what that is, as is evident in Joseph's detailed review of work on identity that spans centuries and multiple disciplines. Joseph (2004, 2006) argues (largely in line with SIT) that our sense of who we are is, to a certain degree, determined by our membership in various groups. In other words, our individual identity is composed of the various group identities (gender, ethnic, professional, etc.) to which we subscribe. But our identities are also constructed by others and for others - they are multiple and dynamic:

Yet there are at least two senses in which each of us undeniably has multiple identities. The first is the universal fact that individuals have various roles with regards to others $[\ldots]$ and in these terms our identity shifts according to the context $[\ldots] .[\ldots]$ The second sense in which identity is multiple has to do with $[\ldots]$ 'consciousness of other selves'. [...] All I can do is to construct my own version of you, based on what I have observed of you, and of others, fashioning all this upon the template of my own unique sense of self. Everyone who knows you or simply comes into contact with you does the same. So there are as many versions of 'you' out there as there are people whose mental space you inhabit. (Joseph, 2004, p. 8)

Joseph offers one interesting personal example of the fluidity of identity in relation to context that might be particularly relevant for biculturals. More specifically, Joseph (2004) discusses the shift in his ethnic/national identity depending on where he is and who he is interacting with (or, in other words, by whom he is being constructed). So, for example, when in England, most of the English he meets identify him as an 
American, but other Americans he meets find his 'Americanness' unconvincing due to the fact that he has lived in England for an extended period of time and does not speak with an American accent. For Joseph, this last point is the key aspect of the link between language and individual identity - though functions of language include communication and representation, "[b]efore either of these, and in many regards enveloping them both, language exists $[\ldots]$ for the purpose of reading the speaker [...], how speakers themselves are read, in the sense of the social and personal identities their listeners construct for them based on what they say and how they say it" (Joseph, 2006, p. 487).

But there is a broader way in which language is linked to identity. As already mentioned, language can be a salient marker of group identity. Though the connection between individual and group identities is complex (a detailed discussion of this link is beyond the scope of this paper), as Edwards (2009), echoing Joseph, puts it, "Our personal characteristics derive from our socialization within the group (or, rather, groups) to which we belong. [...] Thus, individual identities will be both components and reflections of particular social (or cultural) ones [...]" (p. 20). In line with Fishman (1989, 1994) both Joseph $(2004,2006)$ and Edwards (2009) argue for the close link between ethnic/cultural/national identity and language. The link between language and ethnic identity is often discussed in reference to minority group rights and the role language promotion and maintenance play in constructing and maintaining ethnic identities (Joseph, 2004; May, 2001). Discussions of language and national identity are usually linked to the birth of nationalism and the construction of the one-language one-nation myth, which treats language as inherently linked to a national identity. As Edwards (2009) and Joseph (2004) point out, while this connection is less ancient and natural than 
some people realize, language remains one of the most salient components of group identity.

But not all researchers dealing with this topic are convinced that the link is inevitable, or that language is the single most important marker of identity (as Joseph would have us believe). This is especially the case when dealing with immigrant groups for whom the issues of language and identity are quite complex. May (2001) argues that "the language we speak is crucial to our identity to the degree to which we define ourselves by it. This will obviously vary widely, both among individuals and within and between groups. As such, it may well be that some individuals and groups will regard a particular language as a largely superficial marker of their identities and have no great sense of loss in abandoning it" (p. 135, emphasis original). For May, this is exemplified by immigrant ethnic minorities who acquire the language of the receiving country, perhaps at the cost of first language retention, which "would only affect the language use aspect of [their] ethnic identity, not the identity itself" (p. 135). Of course, Fishman would likely disagree with May by saying that, though some form of ethnic identity was retained, this identity has been transformed into something new, because the new language cannot possibly fully express the original culture. May (2001), however, believes that "immigrant ethnic groups may retain their original language as an 'associated' language - one that group members no longer use, or perhaps even know, but which continues to be a part of their heritage" (p. 135).

According to May (2001), the strength of the link between language and identity will therefore depend on individual and group characteristics, as well as the context. In the case of immigrant groups, ethnic language use may range from instrumental to 
symbolic (to both). In other words, the language might be used in important daily communication and be closely linked to enacting an ethnic identity, or be relegated to serve a merely symbolic function, acting as one of many ethnic symbols (such as flags, food, etc.) (May, 2001).

While the link between language and identity is complex, researchers generally agree that the two are interconnected. With the exception of a short discussion by Edwards (2009), the above research does not deal specifically with bilingual biculturals and, therefore, is only of limited use in studying the subtleties of language use among that group. But, as Edwards (2009) says, bilingualism (especially when combined with biculturalism) is particularly interesting and relevant to discussions of language and identity:

For monolingual majority-group speakers in their own 'mainstream' setting, the instrumentality and the symbolism of language are not split and, for most such individuals, the language-identity linkage is not problematic: indeed, it is seldom considered. Minority group speakers, however, rarely have this luxury. For them, matters of language and culture are often more immediate. [...] [A] link will often exist between bilingualism and a heightened sense of awareness of, and concern for, identity. [...] [A] consequence is that the position and the responses of minority groups focus attention on the possibility and, in many instances, the inevitability of a split between the communicative and the symbolic functions of language. You may have to live and work in a new language, a medium that is not the carrier of your culture, or the medium of your ancestry, or the vehicle of your 
literature. Such settings provide an extended relevance to the study of bilingualism and identity. (pp. 254-255)

Though Edwards seems to be referring here mostly to autochthonous minority groups, what he says has relevance for immigrant minorities since they, too, face living in two languages and cultures (this is certainly the case for first-generation immigrants). Edwards does not, however, take the discussion of bilingualism and identity further; to create a more complete picture, the research on language and identity discussed here needs to be supplemented with literature that deals more specifically with the acquisition of an additional language and culture. For this purpose, the writings of bilingual writers and researchers dealing with bilingualism offer some useful insights.

Edwards (2009) refers to the split between the instrumentalism and symbolism of language experienced by bilinguals. As will be shown below, the bilingual experience can be characterized by a number of splits. At the surface level, the separation, or compartmentalization of languages, can be explained by what Grosjean (2010) calls the complementarity principle: "Bilinguals usually acquire and use their languages for different purposes, in different domains of life, with different people. Different aspects of life often require different languages" (p. 29). Language use is, according to Grosjean, domain specific, and for bilingual speakers language choice will often depend on the domain in which they most often used (or learned) a particular language. For example, a bilingual speaker who learned arithmetic and prayer in a particular language will likely continue to use that language for those purposes (Grosjean, 2010). Language choice is also determined by participants (Are they monolingual or bilingual? What is their language proficiency in the L2?), situation (or context), and function of the interaction 
(excluding others, raising status, etc.) (Grosjean, 2010). Grosjean offers a straightforward picture of what governs people's decisions to use the languages at their disposal. But there is a deeper sense in which language choice reflects the bilingual identity.

It must be noted that the link between bilingualism and identity has been generally understudied within the field of linguistics. Bilingualism has traditionally, in a manner that echoes Park's (1928) marginal man model, been associated with a split personality. Though this belief has been questioned, "the view of bilingualism as a problem of two incompatible identities, referred to here as the discourse of bilingualism as linguistic schizophrenia, has not vanished" (Pavlenko, 2006, p. 3). Interestingly, while there has been a shift away from viewing bilingualism as 'schizophrenic' in academic research (a move that likely reflects general trends, as illustrated by the celebration of biculturalism in acculturation research), bilinguals, particularly bilingual writers, continue to use the analogy when describing their experiences living with two (or more) languages: "These explorations reveal that the dominant metaphors and tropes that appear in bilinguals' reflections on language - tongue snatching, border crossing, borrowing, bigamy, betrayal, bifurcation, fragmentation, multiplicity, split, gap, alienation, dislocation, and double vision - reinscribe the feeling of duality and invoke the discourse of schizophrenia [...]" (Pavlenko, 2006, p. 5). As Pavlenko notes, however, this duality is no longer necessarily associated with a continuous, unresolved struggle, but is seen by many of these writers "as a source of both an anguish and creative enrichment, the latter stemming from the ever-present relativity of one's stance and perspective" (or, in other words, the detachment/triangulation that was discussed at the beginning of this chapter) (Pavlenko, 2006, p. 5). 
Motivated by questions of bilingualism's relationship to identity (or 'self', as Pavlenko often terms it), Pavlenko (2006) conducted a large (N=1039) two-year, on-line study. She used a 34-item questionnaire with both closed and open-ended questions to gather demographic as well as language-use related data. In her discussion of the results, Pavlenko (2006) uses descriptive statistics to provide some general information about the participants, but her study really centres on a qualitative analysis of a single open-ended question - Do you feel like a different person sometimes when you use your different language? - to which 65 percent replied that they do, and 26 percent replied that they do not. Pavlenko then compiled a corpus of the replies that went beyond a single word answer; the resulting discourse analysis revealed a number of interesting patterns.

According to Pavlenko (2006), "[t]he presence of several alternative discourses of bilingualism and self constitutes perhaps the most interesting finding in the study" ( $p$. 27). Pavlenko classifies the findings into three broad categories: (i) Linguistic and cultural differences and learning contexts; (ii) Differences in language emotionality and proficiency; (iii) Negative responses and evaluations.

\section{(i) Linguistic and cultural differences and learning contexts}

Participants who were placed in this category were united by the belief that language and culture are inextricably linked, where switching languages entails adapting ones' personality to the cultural norms associated with the language. Participants often related this connection between the two to language socialization. Pavlenko (2006) notes that "[b]oth discourses, one language - one personality and language socialization, display a non-agentive view of the speaker, who does not speak the language but is rather spoken by it" (p. 13). Many of the participants in this group were composed of late 
bilinguals, often immigrants, though Pavlenko does not provide the reader with the exact numbers.

(ii) Differences in language emotionality and proficiency

This category reflects a split in language use that is more complicated and arguably 'deeper' than the one above. According to Pavlenko (2006), "[t]he respondents also invoke another source of different selves that is much harder to interpret, namely, the feeling that the first language is 'real' and 'natural', while later languages are 'fake', 'artificial', and performative" (p. 18). For some respondents, the first language is associated with the private self, while the second one with their public role, the persona they project. The perceived artificiality of the second language might be a result of language proficiency issues, where speaking the first language is simply easier and more natural than speaking additional languages. This split might also be a result of differences in emotional expression. Pavlenko notes that research in psychology and psycholinguistics has shown that, especially in the case of late bilinguals, the first language often elicits a stronger emotional response. This might "stem from affective linguistic conditioning in childhood, when languages are learned with the full involvement of the limbic system and emotional memory. In contrast, languages learned later in life may rely $[. .$.$] on declarative memory and thus [\ldots]$ produce a feeling of detachment" (Pavleno, 2006, p. 23).

While the distinction between an intimate (first) language and a detached/distant/formal (second) language is evident here, in an earlier work, Pavlenko (2005) warns that the dichotomy of the 'us versus them' often found in research on language choice should not be taken for granted: "In my own case, however, the 
dichotomy fails - because for me, and for many others in similar circumstances, the second language has become another language of the self. It is the language in which I grieve, make love [...]" (p. 233). How this language had become the language of the self and emotions is not something that Pavlenko discusses. One could assume that various factors (such as length of stay in a new country, age of acquisition, social networks, etc.) play a role here.

(iii) Negative responses and evaluations

Some of the participants do not feel the language split discussed above and find that their identity (or, their sense of self) remains unitary and unaffected by the language they speak. For many of them, this singularity is something that took time and is a result of a long process of adaptation following immigration.

Pavlenko's (2006) study shows that the link between bilinguals' language use and identity is varied and complex. Even though duality continues to be a dominant theme in bilingual experience, it is now seldom associated with something negative. Pavlenko suggests that anxieties (especially in the works of bilingual writers who wrote in assimilationist settings) "over an inner split may stem from the lack of social acceptance of bilingualism and may disappear once bi- and multilingualism are accepted as the norm, rather than an exception" (p. 28). Here, once again, we are reminded of the potential importance of context in adaptation.

The discussion of language and identity presented in this section is inevitably an abbreviated version of a very complex topic. What I have focused on is the idea that language can have various levels of salience and play various roles in construction of both group and individual identity. This, along with other aspects of biculturalism, will 
inevitably depend on both individual and group characteristics, as well as the context in which they are embedded. Before discussing these in reference to my study, it is useful to review the researchs on the group I am interested in - the Polish immigrants.

\section{Studies of Polish immigrants}

There has been little research done on Polish immigrants. The four studies examined here represent the few recent attempts to provide insight into the immigration experiences of Poles. The studies described deal with different contexts (Italy, England, and Canada) and employ various theoretical and methodological frameworks.

Consequently, not all of them, and certainly not all aspects of them, are directly related to this research project. Their examination, however, is necessary to situate my research within the rather small body of work on Polish immigrants.

Kosic's (2002) quantitative study of acculturation of Croatian and Polish migrants in Italy appears to be the only work that looks at Polish immigrants through the lens of Berry's (1997) model of acculturation. Kosic sets out to determine whether Berry's acculturation strategies (integration, assimilation, separation, and marginalization) effectively describe the experience of the Croatian $(\mathrm{N}=172)$ and Polish $(\mathrm{N}=179)$ migrants. She is also interested in whether, as Berry argues, integration results in the highest psychological well-being of the participants.

Her findings, in line with Berry's (1997) acculturation model, suggest that participants employ one of three strategies (integration, assimilation, or separation). Interestingly, however, she finds no distinction in psychological well-being between integrated and assimilated participants thus, at least within this particular context, refuting Berry's assumption that integration is more positively associated with 
psychological well-being than assimilation. She does note that integrated and assimilated participants scored significantly higher on psychological well-being than separated participants.

In a qualitative study of 30 Polish immigrants in the UK, using semi-structured interviews, Temple (2010) examines how Polish immigrants construct their identity, paying particular attention to language and drawing on, amongst others', Pavlenko's work $(2005,2006)$. Of the 30 first- and second-generation participants interviewed, 17 had a strong sense of their Polish ethnic identity. For others, ethnicity was harder to pin down and was often changeable and context specific (these participants usually identified with both cultures). Salient characteristics of the participants' Polish ethnic identity included "[u]sing the Polish language, being born in Poland, having Polish values, practicing Polish culture, religion and the emotional aspect of being Polish. [...] Although speaking Polish was mentioned as one important part of being Polish, it also 'ran through' the other aspects mentioned" (2010, p. 290). Language could, then, be viewed as a thread linking the various aspects of ethnic identity.

Some participants echoed Pavlenko's (2006) notions of self-translation and commented on how their self was different when using their first and second language. Here again, a link was made between the first language and increased intimacy and emotionality. Language was also used to create an 'us-and-them' dichotomy, especially between recent arrivals and those migrants who were born or have lived in England for a long time. The participants who fell in the latter category felt that their Polish identity was threatened by the new arrivals, who often spoke Polish more fluently and proclaimed that they were 'more Polish' than those who have resided in England for a longer time. 
Temple (2010) argues that the discussion of values, especially in comparisons to English values, was an integral part of identity construction for these participants. These were characterized by both positive and negative comparisons. On the one hand, participants praised English multiculturalism, professional opportunities (a notion that anything could be achieved with hard work), and the "anonymity of England, the freedom from the close ties of Polish communities and the 'yoke' of the Polish Catholic Church" (Temple, 2010, p. 292). On the other hand, some participants felt that the English "are wild and spoiled whereas Polish people are more disciplined" (p. 292), and that the English are also individualistic and distant (Temple, 2010).

Temple (2010) also shows how the intricacies of language choice influence participants' choice (or lack thereof) of social networks. Temple finds that her participants clustered into four distinct patterns of networks: Polish networks, limited choice networks, divided networks, and mixed networks. Those in the Polish networks interacted mostly with other Polish people. All of them reported their English ability as poor and "all unequivocally described their ethnicity as Polish and this group included the participants who made the most negative comments about 'English' values" (Temple, 2010, p. 299). Most of these participants were recent migrants who planned to return to Poland. Those in the limited choice networks had some contact with English people (mostly through work, but occasionally socially as well). These participants, despite describing their English as very good, reported difficulty socializing with the English, claiming that "they seemed not really looking for any contacts with new immigrants" (Temple, 2010, p. 299). These migrants were also uncertain whether they would stay in England permanently. Some of the second- and third-generation participants reported that 
they interacted mostly with the English at work and with both groups socially. They insisted, however, on keeping their Polish and English friends separate because they did not "mix well" due to linguistic and cultural differences (Temple, 2010). A small portion of the participants engaged in mixed networks. "For example, Marta Sacha said that when she went out with Polish friends she tried to take English friends with her. She appreciated the multicultural nature of England and felt that her friends benefited from meeting each other" (Temple, 2010, p. 300).

Temple's research on the social networks lends support to LaFromboise et al.'s (1993) groundedness dimension of BCC as it shows that recent (unintegrated) immigrants have networks limited to members of their culture of origin, while integrated immigrants (who could be referred to as competent biculturals) have networks representative of both cultures. Temple (2010) does, however, point out that first generation immigrants may never get the opportunity to develop social networks beyond those of their culture of origin. She cites linguistic reasons as the main limiting factor of access to new networks, and argues that realities of immigration - the need to find work, for example - limit immigrants' abilities to acquire the language. Consequently, immigrants may feel "that their level of English [does] not allow them to mix with the kinds of people they [feel] comfortable with and serve[s] to stress difference rather than act to bridge the gap between different language speakers" (Temple, 2010, p. 298).

In another qualitative study of Polish immigrants in England, Ryan (2010) examines how "ethnic identity is mediated through language, gender, whiteness and European-ness" (p. 359). Ryan (2010) argues that "[a] key component of ethnic identity is its oppositionality. In other words, a group develops a sense of itself through its 
perceived differences from other groups" (p. 360). Within the context of migration, this sense of ethnicity is coupled with a transformation of ethnic identity caused by contact with other groups, during which there is an interplay between self-definition and the identity ascribed to one by members of other groups. "Hence, migrants may be confronted by negative stereotypes of themselves, as previously valued traits such as language, religion, dress, etc. now become markers of their status as 'foreigners' and 'outsiders"' (Ryan, 2010, p. 361).

Applying these notions of identity to the study of 30 Polish immigrants living in London, Ryan (2010) presents a number of ways in which Polishness is expressed. For some of the participants, Polishness is closely associated with Catholicism, with the Polish churches in London offering a space for enacting Polish identity. The church and, more generally, the enactment of Polish traditions rooted in Catholicism, provide the immigrants with a continuity that may make the initial transition easier, while reinforcing and maintaining their Polishness in the long run. The church is also a social centre where people meet new friends and exchange information related to employment and accommodations (Ryan, 2010).

Other migrants did not find it necessary to attend Polish church and were perfectly content to attend mass in other churches and languages. For some participants, "the intertwining of Polishness and Catholicism was not meaningful $[\ldots]$ and they found other ways of being Polish in London" (Ryan, 2010, p. 364).

The relationship with Poland was, for many participants, a key aspect of their Polishness. But this connection was often "varied and complex" (p. 361). For some, the attachment was characterized by relationships with family and friends. Some alluded to 
the geographical and natural beauty of the Polish forests and mountains. These visions of 'Poland-left-behind' (with all its people and landscapes) were characterized by nostalgia and, while many of the participants were finding ways to fit into their new world, "it is worth emphasizing that adjusting to a new normality does not necessarily obviate ongoing home sickness and desire to return home" (Ryan, 2010, p. 365).

Ryan (2010) notes that only one of the participants had mostly English friends, possibly because he worked in an English-speaking environment. Other participants found it difficult to befriend English people. Echoing the findings from Temple (2010), many of the participants found the English snobbish, "difficult to 'read', private, closed off and hence difficult to get to know" (Ryan, 2010, p. 371). Ryan points out that "[one] common feature to emerge was that friendly relations were often formed with other migrants, though not exclusively Poles" (p. 372). Some participants noted that not all Poles were thrilled about London's multiculturalism. One of the participants said that "in a cosmopolitan environment such as London people needed to be tolerant of each other's differences, and she felt annoyed by the lack of tolerance shown by many recently arrived Poles" (Ryan, 2010, p. 372). The statement implies that tolerance is not something that is necessarily inherent but something that is acquired within a multicultural setting.

Ryan (2010) points to one more construct as key in negotiating Polishness - the 'Pole Abroad'. Many of the participants expressed their disappointment in the poor behaviour of some of the Polish immigrants in London but "often explained [it] in terms of migration, the freedom of the foreign city, and situational ethics, thus clearly defining this bad behaviour in contrast to 'polite', decent, hard working Poles" (p. 374). Though Ryan does not touch upon this, this implies a certain lack of agency, almost as if the 'bad 
Poles' were acting against their 'nature', having been corrupted by their Western surroundings.

Ryan admits that the participants' construction of identity is varied and complex but argues that Polish immigrants define themselves most often in relation (or opposition) to the 'Pole Abroad': "The persistent theme of Poles 'behaving badly' illustrates the key role of stigma in how participants sought to construct their own normalized behaviour and successful adjustment in opposition to their compatriots in London" (p. 374). But the 'Pole Abroad' may not be, as Ryan claims, a simple construct that represents some poorly behaving Polish immigrants, but rather a more complex one that reflects participants' view of certain Western (corrupting) values.

The last study considered here is most relevant to my research in terms of context, as it looks at Polish immigrants in Canada (in the Greater Toronto Area-GTA). In fact, Lustanski (2009) appears to be the only study that looks at Polish ethnic identity in Canada. More specifically, she "investigate[s] how the ethnic self-identity of [first- and second-generation Polish immigrants] has changed in the last two decades" (2009, p. 39). She notes that other (older) studies of Polish ethnicity have characterized language and religion as the most salient characteristics of Polish ethnic identity. To test whether this is still the case, Lustanski uses a quantitative design. The participants included 33 firstgeneration immigrants who arrived in Canada between 1987 and 1993 and 182 'second'generation immigrants of whom 114 were born outside of Canada but arrived before fully acquiring Polish. The participants were given personal questionnaires with questions related to ethnic self-identification, language attitudes and competence, participation in Polish organizations, etc. Ninety percent of first-generation respondents identified 
themselves as Polish with only six percent choosing a hyphenated identity. Of the second-generation participants, 78 percent chose Polish and 16 percent chose PolishCanadian.

For the first-generation immigrants, place of birth was the main reason for identifying as Polish; for them, Poland "symbolizes their past: their childhood, adolescence, and to some extent, adulthood. [...] Thoughts about Poland engage them emotionally [...] Poland per se becomes a kind of ideal country with which most of the first-generation immigrants identify" (Lustanski, 2009, p. 47). The second most important factor was place of birth of parents. Tied for third were Polish customs and language ability. For the second-generation participants the most important factors were (in descending order): having Polish parents (especially dominant for those born in Canada), being born in Poland, respect for Polish traditions and, finally, language proficiency (in reading and writing).

Lustanski (2009) concludes that the Polish language is no longer a key cultural component of the ethnic identity of Polish immigrants. She states that this "means that the Polish minority, at least that living in Canada, would not be defined as ethnolinguistic, but rather ethno-traditional" (p. 50). From a purely methodological perspective, Lustanski is in no position to make such sweeping statements. To begin with, her first-generation participants were drawn from a single workplace (a woodworking firm) and of the 33 participants, 32 were male. This small sample is hardly representative of the Polish minority in Canada (and rather more representative of a group of woodworking males in the GTA). The second-generation sample is drawn from a single school and, therefore, is hardly representative of second-generation Polish immigrants. 
Lustanski spends much of her time comparing the two groups of participants using descriptive statistics. Considering the large difference in group size (33 first-generation versus 188 second-generation), one might wonder whether such comparisons are legitimate. There are also times when she reports data for all participants as a single group - those percentages are skewed for obvious reasons.

Further, Lustanski's (2009) questionnaire is problematic. She begins her assessment of the importance of language as a marker of ethnic identity by studying responses to the prompt: What are your reasons for self-identification with Polishness? a) Born in Poland; b) Polish parents; c) Respect for Polish traditions and customs; d) Interest in Polish culture; e) Interest in Polish affairs; f) Participation in Polish organizations; g) Ability to read and write in Polish. While, arguably, the last item deals with language (or, more precisely, literacy), it hardly captures the more subtle elements of language and identity. This is perhaps why Lustanski supplements this question with another one: What should you do to be Polish? Please mark only one, the most important one. a) teach children Polish; b) respect Polish traditions; c) speak in Polish; d) keep Roman Catholic faith.

Ignoring the already mentioned problems in reporting the data for all participants as a single immigrant group, Lustanski shows that 52 percent chose respect of Polish traditions, 16 percent chose teaching children Polish and 38 percent chose speaking Polish. From this, Lustanski (2009) infers that respecting Polish traditions is more important than language, even though, after performing some basic arithmetic $(38+16=54)$ we see that the results are less obvious. Of course, she treats these items separately and, combining the results with the descriptive data from the previous item, 
comes to the dubious, but confident conclusion that "the analysis of [her] survey does not support the thesis [that Polish is fundamentally linked to Polish identity] at all" (p. 48, emphasis mine).

There are a number of other methodological problems with this study that I will refrain from examining in the interest of space and time. In addition to these, Lustanski (2009) reduces complex issues like language use, culture, and identity to a few simple questionnaire items, likely giving a skewed and incomplete picture of Polish ethnic identity in Canada. It is clear that more research is needed to create a more complete picture of the Polish experience in Canada. 


\section{CHAPTER III: METHODOLOGY}

As shown in Chapter II, most of the research conducted on biculturalism has been either non-empirical (Park, 1928; LaFromboise et al., 1993) or quantitative (BenetMartínez et al., 2002; Hong et al., 2000; Phinney et al., 1997; Phinney et al., 2006; Phinney \& Ong, 2007). One of the few exceptions to this is Phinney and Devich-Navarro (1997), a study that employed quantitative and qualitative methods to create one of the most comprehensive pictures of biculturalism to date. As Phinney and Devich-Navarro (1997) point out, biculturalism is a complex and highly variable phenomenon and any typologies based on quantitative models alone are bound to oversimplify it. One might argue, in fact, that qualitative methodology is best suited for the study of the intricacies of biculturalism.

This study employs an interview-based qualitative method; it fits under what Merriam (2009) refers to as basic qualitative research. This approach is particularly wellsuited for this type of study for a number of reasons. Merriam (2009) says that a basic qualitative study would be interested in (1) how people interpret their experience, (2) how they construct their worlds, and (3) what meaning they attribute to their experience. The overall purpose is to understand how people make sense of their lives and their experiences. (p. 23)

Qualitative research seeks to present a rich picture of a phenomenon and is concerned "primarily with process, rather than outcomes or products" (Creswell, 1994, p. 145). It puts the participants at the centre of the study and gives them a voice, rather than reducing their experiences to numerical data. Finally, qualitative research is, to varying degrees, inductive and, though it should be informed by theory, it is not bound by it and 
its findings need not fit into neat theoretical models (Creswell, 1994). The above reasons make qualitative research well-suited for the study of biculturalism; its use can account for the complexities and variability likely to be found in bicultural experience.

\section{Participants}

This study examines two groups of Polish biculturals - adults and adolescents. Criterion-based selection was used first to identify potential participants. LeCompte and Preissle (1993) state that "[c]riterion-based selection requires that the researcher establish in advance a set of criteria or a list of attributes that the units for study must possess" (p. 69). Since this study looks at two distinct groups of participants, a set of criteria was established for each group:

(i) Adult participants had to have been born in Poland, immigrated to Canada after the age of 20, and had to have been living in Canada for at least 10 years. They also had to be competent speakers of English.

(ii) Adolescent immigrants had to have been born in Poland, immigrated to Canada between the ages of 11 and 17, and had to have been living in Canada for at least 10 years. They also needed to be fluent speakers of English. There are a number of reasons for choosing these particular attributes. First, I wanted to look at immigrants who have been in Canada long enough to become acquainted with local culture and language. Though research on biculturalism does not offer a typical time frame needed to develop a bicultural identity, previous studies have looked at immigrant biculturals who have resided in their adopted countries anywhere from 2 to 20 years (De Korne et al., 2007; Temple, 2010, Tartakovsky, 2009). Ten years was used to maximize the potential participant pool. In the end, however, the participants 
selected had all been in Canada approximately twenty years, making this sample particularly well-suited for studying the biculturalism of long-term immigrant Canadians. Since English was chosen as the medium for conducting the interviews, participants had to be competent speakers of English.

These groups were chosen in order to look at how bicultural identity formation may differ for those who immigrate as adults and those who immigrate as adolescents. According to Phinney (1989) and Phinney et al. (2001), ethnic identity formation takes place during adolescence and becomes largely 'achieved' by young adulthood. Additionally, upon arriving in a new country, adults and adolescents often undergo socialization within different contexts (i.e. school vs. work) and therefore face different challenges and opportunities. The aforementioned factors may result in some noticeable differences in bicultural identity between the two groups. It is important to note, however, that the findings of this research are not generalizable since the sample ( 3 participants in each group) is simply too small. Instead, this study attempts to show what the differences may be for these particular participants. Though the findings may not offer insights about the general population of biculturals, they do, at times, show significant intragroup consistency and intergroup differences. Because of this, this study may be treated as exploratory research, a preliminary look at how biculturalism manifests itself within two different groups of immigrant biculturals.

Snowball sampling (LeCompte \& Preissle, 1993) was used to recruit participants who immigrated to London, Ontario in the late 1980s and early 1990s. The researcher's existing networks were used to find members of the Polish community. Potential participants were contacted through email or by phone and, if interested, were sent a 
letter of information outlining the purpose and procedure of the study. Six participants were selected - three (two male and one female) for the adult group and three (two male and one female) for the adolescent group. The participants will be described in more detail at the beginning of Chapter IV (Results and Discussion).

\section{Data Collection}

Data were collected in accordance with the Tri-Council Policy Statement: Ethical Conduct for Research Involving Humans and the Carleton University Policies and Procedures for the Ethical Conduct of Research. The ethics clearance was received on December $2^{\text {nd }}, 2010$, after which sampling and interviewing began, ending in March, 2011. At the time of the interview, participants were provided with consent forms (see Appendix A), which described the study in detail and gave important information regarding data collection and storage, as well as anonymity and withdrawal procedures. In line with Tri-Council policies, all participants were assigned pseudonyms.

Data for this study were collected through a brief biographical questionnaire and six semi-structured interviews, which lasted from 30 to 60 minutes and were carried out at various locations (ranging from participants' homes and the researcher's home to more 'neutral' locations such as coffee shops). The questionnaire (see Appendix B) was administered at the end of each interview and asked for various demographic data and self-assessment of both Polish and English language skills. This information was used to supplement the data gathered from the interviews. The interviews were recorded in MP3 format using a digital voice recorder and transcribed verbatim by the researcher.

Semi-structured interviews were chosen for their flexibility. As Merriam (2009) points out "[l]ess structured formats assume that individual respondents define the world 
in unique ways" (p. 90). Though the overall structure of the interviews and the types of questions asked were informed by specific theories (as outlined in Chapter II Understanding Biculturalism), many of the questions were open-ended, allowing the participants to respond in new and unforeseen ways in describing their biculturalism. The goal was to conduct the interviews in a manner that resembled conversation, not restricting respondents to reply only in relation to a preconceived theoretical framework, but rather allowing them to construct unique realities. As Merriam (2009) states, this "format allows the researcher to respond to the situation at hand, to the emerging worldview of the respondent, and to new ideas on the topic" (p. 90). A sample list of questions can be found in Appendix C.

\section{Data Analysis}

The data were analyzed drawing on Tesch's (1990) eight steps of qualitative data analysis, as well as aspects of the constant comparative method as described in Strauss and Corbin (1998). Merriam argues that though it was initially developed for grounded theory, "the constant comparative method of data analysis is inductive and comparative and so has been widely used in qualitative research without building a grounded theory" (2009, p. 175). Not all aspects of the method were used in the analysis and so only the relevant ones will be described below.

First, following Tesch's advice, all the transcripts were read to get a sense of what was in the data. Of all the transcripts, the shortest one was picked for closer analysis, which involved initial coding, often referred to as open coding. As Strauss and Corbin (1998) observe, "during open coding, data are broken down into discrete parts, closely

examined, and compared for similarities and differences" (p. 102). Open coding draws on 
multiple sources (theory, exact words used by researcher and participant, interpretation by researcher) in constructing initial categories (Merriam, 2009). During analysis, open coding involved taking descriptive notes in the margin of each transcript (e.g. observing Polish traditions, speaking Polish, etc.).

Tesch (1990) highlights the importance of reducing the number of codes into a few larger categories, as this makes data more manageable and highlights important relationships. During the second round of coding, the initial codes were placed into larger categories. For example, the codes mentioned above formed a larger category (ways of being Polish or enacting Polishness). This was again done for all the transcripts. The third round of coding further reduced the number of categories, which now reflected both the theoretical framework discussed before (examples of categories include ethnic identity, national identity) and categories that emerged from the data (language, Poland, Canada). It is important to note that the depth of data generated for some categories (like language and social networks, for example) required a return to theory, since the literature reviewed at the time of coding did not adequately address some salient aspects of the bicultural experience. This highlights the non-linear nature of qualitative research, where all parts of a project continuously interact with and inform each other (Merriam, 2009).

The final stage involved several rounds of axial coding. Strauss and Corbin (1998) explain that "[i]n axial coding, categories are related to their subcategories to form more precise and complete explanations. $[\ldots][\mathrm{R}]$ ather than standing for the phenomenon itself, subcategories answer questions about the phenomenon such as when, why, who, how and with what consequences [...]" (pp. 124-125). At this stage, part of the coding 
process involved recoding the subcategories found in open coding. New subcategories were created based on consistency and amount of data available across participants. If two or more participants discussed a related subtheme, this would constitute a subcategory. As outlined by Strauss and Corbin above, an effort was made to establish a relationship between each subcategory and the major category to which it belonged in order to create a complete and coherent framework.

\section{Managing bias: The role of the researcher}

One of the main characteristics of qualitative research is that the researcher acts as the main instrument. In qualitative studies, it is the researcher who collects, interprets, and analyzes the data and though his/her unique perspective is useful, it is important to recognize that "the human instrument has shortcomings and biases that might have an impact on the study. Rather than trying to eliminate these biases or 'subjectivities' it is important to identify them and monitor them as to how they may be shaping the collection and interpretation of data" (Merriam, 2009, p. 15). Here, I must once again confess that my contact with bicultural Polish immigrants extends beyond the participants in this study. Biculturalism and immigration are topics with which I am well acquainted and with which I have dealt daily for the last twenty years. In a sense, the participants, grouped as they are into two categories - the adults and adolescents - represent me (13 when I arrived in Canada) and my Polish-Canadian friends, as well as our parents (well into their adulthood when they arrived here). This project is, therefore, in many ways personal.

But this is not necessarily a limitation. McCracken (1988) argues that, though that "deep and long-lived familiarity with the culture under study has, potentially, the grave 
effect of dulling the investigator's powers of observation and analysis, [...] it also has the advantage of giving the investigator an extraordinarily intimate acquaintance with the object of study. [It] gives the investigator a fineness of touch and delicacy of insight that few ethnographers working in other cultures can hope to develop" (p. 32). McCracken, in line with Merriam (2009), also stresses the importance of questioning the preconceived notions one has about that intimate topic under study and coming to terms with the biases one brings into the research. I would like to say that I have given these issues sufficient consideration and have, to a large extent, achieved what Patton (2002) terms 'emphatic neutrality', that "middle ground between becoming too involved, which can cloud judgment, and remaining too distant, which can reduce understanding" (p. 50). 


\section{CHAPTER IV: RESULTS AND DISCUSSION}

In the previous chapter I argued that biculturalism is best studied using a qualitative methodology because of its complexity, a complexity poorly accounted for by quantitative constructs. The data analysis reveals this to be true, as the themes that emerged from the interview data give a more intricate and comprehensive account of biculturalism than that found in the quantitative studies reviewed in this paper. Many of these themes loosely reflect concepts examined in Chapter II, but the analysis goes beyond the literature discussed there and offers a deeper and richer depiction of biculturalism, or at least what it means to be bicultural for these participants. This chapter is divided into four sections:

Section 1 offers a short description of the participants, including information drawn from the biographical questionnaire distributed during each interview.

The thematic analysis begins in section 2 with the discussion of cultural identity. This section is informed by Phinney and colleagues' work on biculturalism and immigrant acculturation, focusing on the dichotomy between ethnic (Polish) identity and national (Canadian) identity. The data analysis in this section, however, shows that the construction of the two identities is quite complex - more complex than has been accounted for in the existing literature - and therefore reveals some limitations to Phinney's framework.

Section 3 accounts for these shortcomings by highlighting other characteristics of biculturalism. This includes a discussion of hyphenated identity based on Benet-Martínez et al. (2002); an examination of various aspects of living in (between) two cultures, drawing mainly on the work of Hoffman (1986), LaFromboise et al. (1993), Pavlenko (2005, 2006), and De Korne et al. (2007); a discussion of social networks based on Wei 
et al. (2007) and Temple (2010); and, finally, a section on language and biculturalism that draws on May (2001), Joseph (2004), Pavlenko (2005, 2006), Edwards (2009), and Grosjean (2010). These themes and sub-themes are only in part informed by theory as the analysis is, of course, largely driven by what the participants say, moving the analysis of biculturalism beyond theory.

Section 4 presents a concluding discussion of the results, bringing the analysis together to create a coherent picture of immigrant biculturalism.

\section{Participant Biographies}

\subsection{Adolescent group}

Marek (Mark):

Marek arrived in Canada in 1991 at the age of 17. He spent three years in Germany prior to immigrating to Canada and had little knowledge of English upon arrival. He studied in an ESL program after arriving (in high school). Marek has a BA in political science from a Canadian university. He currently works as a manager for a grocery store. He self-rated all four language skills at six on a scale of one to seven for both languages.

Beniamin (Ben):

Beniamin arrived in Canada in 1990 at the age of 13 (directly from Poland). He did not know English upon immigrating and studied ESL for three years in Canada. Beniamin has an undergraduate degree in criminology and psychology and a master's degree in education from Canadian universities and currently works as a teacher. He rated all of his English language skills at 7/7 and Polish language skills at 3/7 for writing, 4/7 for reading, and 5/7 for listening and speaking. 
Katarzyna (Kasia/Katy):

Kasia arrived in Canada in 1990 at the age of 11 (directly from Poland). She did not know English and studied in an ESL program for two years in Canada. Kasia has a BSc in computer science and is employed as a computer programmer. She rated her English language skills at $6 / 7$ for speaking and $7 / 7$ for reading, writing, and listening and her Polish language skills at $6 / 7$ for both speaking and writing and $7 / 7$ for both listening and reading.

\subsection{Adult group}

Norbert:

Norbert arrived in Canada in 1988 at the age of 24 after spending two years in Greece. He studied English in high school and university in Poland. Norbert has a master's degree in modern languages and Polish literature from a Polish university but did not work in Poland. He has not studied English formally in Canada, nor has he attended any schools. He works as a truck driver. He rated his English language skills at 5/7 for speaking and writing, and $7 / 7$ for listening and reading. He rated his Polish at $7 / 7$ for all skills.

Elżbieta (Elizabeth):

Elżbieta arrived in Canada in 1991 at the age of 34 after living in Germany for five years. She did not study English before her arrival but did attend ESL classes in Canada for two years. Elżbieta has a master's degree in communication from a Polish university and worked as a teacher in Poland. Outside of language classes, she has not attended school in Canada. She works in retail. She rated her English language skills at 5/7 for speaking and writing, 6/7 for reading, and 7/7 for listening; she rated her Polish at $7 / 7$ for all skills. 
Karol:

Karol arrived in Canada in 1990 at the age of 37 after spending three years in Germany.

He studied English in Poland for 10 years in high school and university and has a master's degree in physics from a Polish university. He worked as a teacher in Poland but has not attended school in Canada. He is currently employed as a maintenance worker at a university residence. He rated his English at $5 / 7$ for listening and speaking and $6 / 7$ for reading and writing. He rated his Polish at 7/7 for all skills.

\section{Cultural identity: Ethnic versus national}

Data analysis revealed that the participants perform a number of actions and draw on multiple resources in enacting and constructing both their ethnic (Polish) and national (Canadian) identities. In discussing the former, these can be broadly grouped into four categories: (i) participants' actions and behaviours that reflect their 'Polishness' (enacting Polishness), (ii) sense of pride and belonging to their ethnic group (pride and belonging), (iii) memories of old Poland/perceptions of new Poland (Poland: old and new), and (iv) positioning in relation (or in contrast) to 'typically' Polish characteristics (relation to Polish character).

\subsection{Constructing Polish (ethnic) identity}

\section{Enacting Polishness}

The responses used for this section were elicited by explicitly asking the participants to describe their 'Polish' behaviours. As mentioned above, the participants do a number of things to express (or maintain) their Polish identity in Canada. Examples of these include following various Polish Catholic traditions and holidays (Elżbieta, Beniamin), participating in Polish-Canadian cultural organizations (Elżbieta, Norbert, 
Kasia), having Polish friends (Elżbieta, Marek, Kasia), maintaining links with Poland (Karol, Beniamin), and speaking Polish (Elżbieta, Karol, Marek, Kasia). Interestingly, with the exception of speaking Polish, there is little consistency in their replies. Further, it should be noted that using Polish was explicitly named as a characteristic of being Polish. In other words, when asked what they do that is Polish, four out of six participants listed using Polish first:

Elżbieta: Well, being Polish for me is, we definitely ninety percent of us, meaning our friends, family, not so much children anymore, but my husband and my friends, we definitely speak more Polish among us than English.

Karol: So basically we can stay Polish and use only Polish language - watching Polish $T V$, listen to Polish radio online, read Polish magazines online, Polish news online and watching movies.

Marek: Hmm, what makes me Polish? Well, of course when I meet with my parents we speak Polish.

Kasia: Ummm... what I do that makes me Polish? [...] I read and write and communicate in Polish on a daily basis [...]Friends and family, the same thing, I talk to them in Polish even people I can speak to in English at times I will speak Polish with because it's easier to communicate that way sometimes.

For most of the participants, using Polish is perhaps the most salient part of their ethnic identity. Other important aspects that were suggested in their answers were having Polish social networks and maintaining ties with Poland (following Polish events and staying in touch with family and friends), but these were not explicitly identified by all of the participants as key to 'being Polish'. Finally, the participants draw on two types of 
Polish culture in enacting the ethnic identity: Polish-Canadian (involvement in Polish community in Canada) and 'Polish-Polish' (represented by maintaining links with Poland, usually through modern media).

\section{Pride and belonging}

All of the participants had a favourable view of their ethnic group, especially when looking through the eyes of the majority. That said, both participant groups also briefly commented on some negative Polish stereotypes and experiences they have had with them. This was clearly explained by one of the adolescents:

Kasia: Do you every now and again hear someone say, "You're such a Polak, " yeah I do, and obviously it's a negative connotation. Do I hear, you know, a joke, like what's the difference between a Polak and a Newfie? Yeah, every now and again you hear that.

Though other participants made similar comments they also indicated that the negative Polish stereotypes have mostly disappeared or do not quite apply to the Canadian context.

Elżbieta: I would say definitely much better than they used to be. Because the Polish jokes from 50 years ago, they do not exist anymore.

Karol: I think that the way Canadians see Polish people and Polish community has changed over the years. Like, you know, I came here I experienced some jokes, you know, the famous Polish jokes and so on and so on.

Beniamin: In Chicago, I've been there a few times, Poles are viewed less favourably because they have a large Polish community and most of them are not that well off; they're not very well educated, so I guess in the States they might perceive that differently. 
Two major themes are visible above: change and education. In fact, the data show that participants view the favourable perception of Polish immigrants as a direct outcome of the increased level of education of both the Polish adults who immigrated in the $1980 \mathrm{~s} / 1990 \mathrm{~s}$ and their children.

Elżbieta: There are so many successful Polish people, here in London, or Mississauga. If we have in London 17 Polish pharmacists, and eight Polish doctors and those are people who were not educated here, they came from Poland with their degrees [...]. Because those people who got integrated with Canadians; those people are successful and they give very good impression of Polish people because we are smart, we are successful. We only came to Canada 20 years ago and we succeeded so much.

Karol: [O]ver the years when our children started education here and they graduated from universities more and more Polish people get very significant positions everywhere, on each level, in the government, everywhere. So, I think it's rather positive.

Kasia, echoing the words of the adults above, downplayed any negative perceptions of Polish immigrants, choosing rather to "focus on the positive" by highlighting the fact that most of her Polish-Canadian friends, who had arrived in Canada as children, are well-educated and successful. According to Elżbieta, another reason for the favourable perception is the Poles' ability to integrate into Canadian society and succeed socioeconomically. Other participants also drew on similar positive examples when discussing their ethnic group:

Marek: I know the mayor of Mississauga, she's very fond of the Polish community. She said one thing that I really liked, that Poles have really contributed to the development of 
this city of Mississauga. And if you can contribute to the development, a healthy kind of development of any city then that's a good comment.

Participants' experiences dealing with other Canadians generally mirrored the positive perception of Polish immigrants expressed (and experienced) by both groups, and there were few reports of discrimination. In light of such positive descriptions of their ethnic group and generally positive intergroup interactions, it is not surprising that all of the participants said that they are proud to be Polish. Consequently, it may be concluded that they attach value to their membership in the Polish community and have a positive ethnic identity.

\section{Poland: old and new}

The interviews also indicated that Poland - the idea of Poland, the memories of Poland - is a salient aspect of the participants' ethnic identity, particularly for the adults. Memories of youth in communist Poland are charged with emotion and, as Elżbieta puts it, bring some Polish people in Canada together, grounding them in a similar (lost) reality of an old Poland that no longer exists. For another adult, Norbert, thoughts of Poland and return visits to Poland evoke a sense of loss, of family and friends left behind.

Norbert: When I left Poland 23 years ago, the trees in front of my high-rise building were a little bit taller than I am. After 23 years these trees are reaching fifth or sixth floor. You cannot see through those trees what's going on around you; when I was young you could see a few streets down the road because everything was so small. Right now everything changed. I feel lost when I go there from time to time because I don't recognize the places. I don't recognize the people and I don't recognize streets because they changed names, squares changed names, a lot of changes occurred. 
The adult participants' Polish identities are rooted in old Poland, not in new Poland - a place that they find largely unfamiliar. For them, the transformation Poland has undergone is tremendous and a return would be "like immigrating all over again" (Karol, Elżbieta). Though the adults' identities seem partially rooted in a communist Poland, they acknowledge that these identities are no longer the way they once were, that their Polishness has undergone some significant changes and it, much like old Poland, no longer exists in the form it once did. Elżbieta talks about how she is no longer nosy and emotional, while Norbert discusses how his ideas about tolerance have undergone transformation since immigrating.

For one of the adolescents, Poland is important because it is the place of his birth: Marek: I do love the country, Poland...ummm, because I come from it. [...] And obviously we have some attachment still because this is where we were born. This has some meaning. This is where we have spent the first, many people would claim, the most important years of our development. So there is this first, this aspect of 'the first'. But for other adolescent participants, old Poland did not come up and new Poland, though nice for a short visit, is not a place in which they want to live due to a lack of opportunities, a lack of stability, and a different (non-Western) mentality. This is particularly clearly articulated by Kasia and Beniamin, who claim that they could never achieve the level of financial independence in Poland that they have in Canada, and that their peers in Poland, despite their high levels of education, lack similar opportunities.

\section{Relation to Polish character}

The above discussion gives an initial sense of how ethnic identity is constructed by the participants. The data presented thus far are fairly straightforward, but there are 
more subtle ways in which the participants negotiate their ethnic identities. One of these is related to how they define Polishness or the Polish character (and behaviour), and how they position themselves in relation to those definitions. Throughout the interviews, Poles are defined by the participants as emotional, open, hospitable, nosy, impolite, self-aware, and family-oriented. Other characteristics include being mistrustful of authority, drinking, complaining and being solemn. Again, there are no consistencies in how the two groups define the Polish character, and the answers vary from participant to participant. However, the participants consistently distinguish between themselves and 'other' Poles, and they do this in two ways. A good example of how this is done is seen in Elżbieta's discussion of Polish characteristics:

Elżbieta: I think Polish people who are like me, people who were born in Poland and came to Canada 20-25 years ago, they are different now from 20 years ago. We better understand this culture - that people are different from us and we are different. You know, everybody is kind of laid back, doesn't show those emotions anymore like we used to. [...] I still think many Polish people are still like that because they don't have those avenues to Canadians. [...] [In Poland] people are little bit different. They are like we used to be 20 years ago. They want to know everything. So, we are not like that anymore.

Elżbieta makes a distinction between Poles like herself and other Polish people, a group that seems to include those who remained in Poland and those who have not quite integrated in Canada. This is done both explicitly and through the use of pronouns, as she distinguishes between 'us' (using first person referencing) and 'them' (using third person referencing). Another adult, Karol, used a similar technique to distance himself from other Polish immigrants: 
Karol: I met many Polish people who don't have very positive opinion about Canadians. But I notice that most of the people are Polish people who didn't, they didn't integrate very well in the Canadian community and culture. And their English is still not very good.

The distinction between 'us' and 'them' is perhaps most clearly elaborated in Elżbieta's and Karol's words, but the adolescent participants also expressed similar attitudes. Marek, Beniamin, and Kasia also used third person referencing:

Marek: I think Poles still experience that problem, that they do have a problem with authority, with accepting authority. They are not easy to run.

Beniamin: I guess back home, when I go back, it's more family-oriented society but people are more, I don't know, they don't think of the future as much.

Kasia: In one respect people in Poland are a lot more open and hospitable but on the other hand they still haven't learned the western way of doing things.

The above quotes again show the participants' disassociation from Poles in Poland, mostly through the use of third person referencing. The interview data show, in fact, that the adolescent participants rarely use first person referencing when discussing their ethnic group. For the adult members, the disassociation through pronoun use is mostly done when discussing unintegrated Polish immigrants (and to a lesser degree people in Poland), while first person referencing is often used to refer to integrated Poles in Canada (as was illustrated by Elżbieta above). The other adult, Norbert, uses 'we', 'us', and 'our' in most situations when talking about Polish people (both in Canada and in Poland). This suggests that the adult participants have a stronger sense of their ethnic identity, but more importantly, the data show that all of the participants, to varying 
degrees, disassociate with monocultural Polishness in constructing their identities. This indicates that the participants are 'different' than both the unintegrated Poles in Canada and the monocultural Poles in Poland. They have acquired a second culture and their biculturalism is distinct from, and poorly described by, monocultural typologies. This point, along with the theme of change/integration (in Elżbieta's and Karol's quotes), will be examined further in the discussion on biculturalism.

\subsection{Constructing Canadian (national) identity}

Overall, the data pertaining to the participants' national identities were more difficult to organize and interpret than the data on Polish identity. There was generally less consistency in how the participants constructed their national identities and, overall, less data. Though, arguably, the data could be organized into a number of similar subsections, there is simply too much overlap and not enough consistency to do this effectively. I will therefore refrain from using headings but will try, where possible, to loosely centre the discussion on categories that were present above. The fact that these data were harder to work with may, in itself, be meaningful. This will be discussed after examining the findings in more detail.

\section{Participants' Canadian identity}

When asked explicitly what being Canadian means to them (or, what they do that is Canadian), participants offered inconsistent, vague answers. Examples include watching Canadian television and being aware of Canadian politics/events, attending unspecified cultural events, camping, skating, watching hockey, and loosely following traditions such as Thanksgiving and Halloween. Although these answers show little consistency across groups and participants, there is an important theme (one that will 
come out more clearly later) that begins to emerge - Canadian multiculturalism. Two of the adults had this to say when discussing their culinary habits in Canada:

Karol: Now, over the years we learned different cuisines. Not only Canadian, but you know, it's an international community here, like Italian or South American food. Elżbieta: I accommodate many, because I love to cook, many Canadian recipes, not really Canadian, because Canada is multicultural. So all the Canadians I know, they are from different countries because they came to Canada like we did but they, you know, they treasure their traditions, like recipes.

Both groups of participants refer to the multicultural nature of Canada throughout the interviews. For example, Marek talks about the difficulty of defining Canadian culture because it is composed of so many other cultures. Kasia talks about having friends from all over the world. Norbert goes even further by saying that "it's hard to find a true Canadian."

Norbert: The majority of us are also immigrants from other countries so, when I interact with people from Columbia, I interact basically with Columbian-Canadians, or, when I interact with Portuguese people, I interact with Portuguese-Canadians.

The participants acknowledge that Canadian diversity has changed their behaviour and that becoming more tolerant of other cultures, more accepting of different outlooks, was for them part of becoming Canadian and has become a part of their Canadian identity. This point was made by Marek, Beniamin, Elżbieta, and Norbert. Other examples of acquired Canadian characteristics include becoming more laid back, less emotional and more distant, becoming more aware and critical of things like littering 
due to private ownership of property (versus public ownership in communist Poland), and being more politically correct.

It is also important to note that the participants generally distinguished between two types of Canadians - the immigrant-Canadians and Anglo-Canadians. The data suggest, perhaps not surprisingly, that participants often identified with the former and not the latter, and had much more contact with other immigrants than with AngloCanadians (this was particularly true for the adult group, but was also true to an extent for the adolescents). It may be argued that, for these participants, enacting Canadian identity revolved mostly around multiculturalism.

As already mentioned, Canadian multiculturalism was a particularly important characteristic in shaping the participants' national identities. Since Canada was seen as predominantly multicultural, the participants felt included. In fact, it seems that most of them defined being Canadian as being from somewhere else, having a hyphenated identity. Taking this definition of Canadian identity into account, it is not surprising that the participants 'felt' Canadian. Discussing this issue was particularly interesting with those who had stayed in Germany prior to their arrival in Canada. When asked whether she feels Canadian, Elżbieta replied:

Elżbieta: I used to live in Germany for 5 years - so, maybe that would be easier to answer that question. Definitely, it would be for me much more difficult to become German than Canadian [...] [b]ecause, they are not allowing you to feel German. They let you in formally and eventually, after fifteen, twenty years they make some exceptions and give you citizenship but you don't feel German. You feel Canadian, I do. 
Elżbieta goes on to say that she feels Canadian because she feels included in Canada's multicultural society. She perceives Canada as a multicultural nation that is more accepting of diversity than that found in Germany. Marek also comments that he was pleasantly surprised, after spending three years in Germany, to find Canadian peers generally accepting of cultural diversity. He reasoned that the Germans were more 'selfaware', suggesting that their strong sense of German identity was related to lower acceptance of cultural diversity. Karol had this to say regarding the differences between Canada and Germany:

Karol: As you know there are lots of historical reasons why we didn't feel well there at the beginning. After some time we made lots of German friends and found out they were very nice people but being an immigrant in Germany wasn't easy-you could feel that everywhere (for instance sprayed signs on the walls "auslander raus"). Canada is different and we felt home just after arriving here.

Another theme that emerged in discussions of Canada was the idea that Canada is a 'land of opportunity' and stability where, with hard work, one can achieve material well-being and develop in ways not possible in Poland. This was discussed by one of the adults (Elżbieta), but the theme was particularly important for the adolescent group, often in contrast to the lack of opportunities in Poland.

Beniamin: Here in Canada I really think for the future. I have my RSPs planned out. I have my pension plan going. We are just selling our home and upgrading to a bigger house and building a new home. I'm thinking of investing and having a better life for my children. I want to have money put away and I just want to live a comfortable life. I think that's the Canadian way. 
Kasia: I'm 31, about to turn 32. I have a good career; I have a good job; I have my own house; I have investments; I have opportunities. If I don't like this job, I pick up and go somewhere else. I don't have to worry about what I'm gonna do. [...] I just think Canada is an easier place to live in.

For these participants being Canadian entails being financially independent, thinking about financial security in the future (i.e. investments, retirement savings, etc.), and having a comfortable, safe life. Canada is "an easier place to live in" (Kasia) and all of the participants (both adult and adolescent) seem content living here, and have no plans to leave - they view Canada as their home and country. This is perhaps most clearly articulated by Karol: I feel very well here. I feel at home here. I can't explain it. Last time when I was in Poland two years ago, when I was there for three weeks, after two weeks I wanted to go home. Maybe home is where your family is, that's why, maybe.

There is, of course, some criticism of 'typically' (Anglo) Canadian characteristics, which include lack of awareness of local and historical issues, high levels of formality/politeness, and strict rules about personal space and political correctness. The participants who comment on these (Norbert, Elżbieta, Kasia, and Beniamin) seem to dislike these traits and have resisted acquiring them.

Norbert: In some countries, people are not afraid to express their opinions more freely and I don't think Canada is like that.

Kasia: Going over to my Canadian friends, you're invited at 3 pm and the invitation says 3-6pm, nobody sticks around after 6pm. It's like, that's what you were invited for, that's how long you stay. It's a very strict, strict rules about personal space and this and 
that...the political correctness in Canada, I think is just ridiculous. It's, you know, the things that you have to watch when you say because everybody takes things personally. Beniamin: Let's say, you know, like these people usually don't share things, right, like when they invite you for dinner, I mean, they expect you to pay. Like when I throw a birthday party, I mean, everything is free.

Here, as when he was discussing ethnic identity, Beniamin distances himself from Canadians through third-person referencing, claiming that he is not like 'these people'. After examining first/third person referencing in the data on Canadian identity, it seems that participants both distance themselves from the Anglo-Canadians in favour of inclusion in the immigrant-Canadian group, and vice-versa. There are times when participants identify with mainstream Canadian culture, referring to other immigrant groups (particularly new, non-European immigrants) as 'they' and to themselves as 'we' ('we' Canadians think this about 'them' immigrants). This is perhaps most strongly illustrated during Norbert's discussion of Canadian multiculturalism:

Norbert: But, when you apply for a job as policeman in Canada, where the police uniform says that you have to have a certain hat, and you want to be a policeman using your own hat...one or the other. You came here, this is our way how the policeman should look like. Maybe in your country policemen wear those things but not in our country.

Overall, the participants' Canadian identities seem less clearly articulated than their ethnic ones. This is perhaps a reflection of the difficulty of defining Canadian culture (which is younger, more diverse and multiple than Polish culture), something that participants allude to numerous times during the interviews. But their Canadian identities might be less clearly defined because they are linked to mainstream culture, a culture that 
is all around them. Maintaining their Polish identities, on the other hand, requires acting in ways that are different (non-mainstream); it requires actions linked to a place outside of Canada. When speaking of enacting identity in particular, these actions might therefore be easier to articulate since they stand out against a uniform backdrop. The discrepancy between how the two identities are articulated might also reflect that the participants' ethnic identities are stronger than their national identities. After all, they are firstgeneration immigrants who remain firmly grounded in the Polish community and retain ties with Poland.

\subsection{Overview of cultural identity}

For Phinney and colleagues the discussion of biculturalism begins and ends with ethnic and national identities. The analysis above suggests, however, that Phinney's dichotomy (ethnic versus national) has limitations for describing biculturalism because the participants construct their ethnic and national identities in complex and multiple ways. The analysis demonstrates that the two identities are articulated differently. Phinney and colleagues study cultural identity focusing mostly on the enacting of identity and the sense of pride/belonging to a group. The above data show that identity construction goes beyond those simple criteria and is far more complex than could be accounted for in quantitative models of acculturation research. Phinney's view of culture is too monolithic to adequately describe the experiences of these participants. Ethnic and national identities are fluid - there are times when participants separate themselves from each culture, and there are times when they identify with one or the other, or both. And this is perhaps the most significant finding thus far: that both groups at times distance themselves from both Polish and Canadian (mono)culture and identify with a new, hybrid 
biculture. They view themselves as being of two cultures, being bicultural. In other words, Phinney et al.'s framework alone is inadequate for describing biculturalism because it does not consider the intricacies of the experience. It is not enough to simply state that participants have both Polish and Canadian identities, that using Polish is a salient part of their ethnic identities, that they have Polish and Canadian social networks, that they use both languages and that they are therefore competent biculturals, or integrated immigrants. While all of the above is true for these participants, and may prove that cultural acquisition is, in fact, non-linear and that immigrants can happily exist within two cultures, there is much more to say about biculturalism. The section below fills in the gaps.

\section{Biculturalism}

\subsection{Hyphenated identity}

According to Benet-Martínez et al. (2002), key to the study of bicultural identity is the participants' self-identification as a member of a particular group. Biculturals who view themselves as part of a hyphenated culture are said to have an integrated bicultural identity (high BII); they view their two cultures as complementary and do not feel as though they are moving between two worlds (Benet-Martínez et al., 2002). The choice of hyphenation as a label is an initial indicator that individuals are, in Phinney and Devich Navarro's (1997) words, blended biculturals, or integrated biculturals according to Berry (2005). When asked to identify themselves in terms of nationality, all of the participants chose a hyphenated identity. The label Polish-Canadian indicates that the participants identify with both cultures (have a hyphenated identity) and the discussion above does 
suggest that this is the case, though the identification with each culture is complex. The adult participants provided a number of reasons for choosing this label:

Karol: In my heart I'm always Polish but as a Canadian citizen, because of the fact that I live here for 21 years, so I think that I am more Canadian than Polish. Taking into consideration my life and where I'm staying and what languages I'm using, I think Polish-Canadian is the best description.

Norbert: I feel Polish-Canadian. I live in Canada; I'm not Polish only anymore. Elżbieta: I think the description is according your emotions. So my emotions are... when I get all of a sudden... when I got upset or angry, I start to think in English, when at some point it was impossible because my emotions went to Polish language, Polish thinking, and now it's the opposite.

Both Karol and Elżbieta allude to the connection between language and identity, though this link is explored in greater depth by Elżbieta, for whom language is closely linked to emotions, and whose inner voice alternates between Polish and English. Karol and Norbert also state that the label is fitting simply because of citizenship and place of residence. Visible in all answers, however, is the theme of transformation from Polish to Polish-Canadian - as Norbert puts it, Polish-Canadians are "not only Polish anymore." This theme returns throughout the interviews and is most clearly articulated by Elżbieta and Norbert. Elżbieta focuses on how her behaviours have changed during her stay in Canada:

Elżbieta: I think the first thing which made me understand I'm getting towards Canadian more than Polish, I smile a lot. [...] I smile all the time. And in Poland, nobody smiles. 
Both Norbert and Elżbieta discuss how part of becoming bicultural entailed noticing and accepting cultural differences.

Norbert: That's part of noticing that I have to behave or I behave here differently because of economic circumstances or political or simply I changed because I noticed that people around me are different in a better way, not in a negative way.

With the exception of Marek, the idea of change is not discussed by the adolescent group. Kasia states that she feels Polish-Canadian because she was born in Poland but now lives in Canada and has Canadian citizenship. Beniamin provides similar reasons but adds that he "was raised back home [...][but his] higher education came from Canada." For Marek, however, arriving at a hyphenated identity was a more complex process.

Marek: Initially I considered myself Polish. And then, for the many years that I have spent here, I think I have come to a certain point where I started thinking about whether I am Polish or Canadian and I think I have a trace of both at this point.

For Marek and the adult participants, a hyphenated identity is a result of conscious and 'documented' change, perhaps because they had an established monocultural identity upon arrival in Canada (recall that Marek is the oldest of the adolescents and came to Canada at the age of seventeen). But it is not clear whether age plays a role here as there may be various other factors at work. What is clear, however, is that language is not explicitly linked to biculturalism by the adolescents, who instead focus on citizenship, place of residence, and socialization as markers of their hyphenated identity. Finally, while the above discussion suggests that both groups of participants are 
blended biculturals, it should be treated as preliminary; a closer examination of the data yields a fuller understanding of the participants' biculturalism.

\subsection{Living in (between) two cultures}

Being bicultural inevitably involves participating in two cultures - a duality that is both actively maintained and passively experienced by the participants. In actively maintaining biculturalism, the participants make conscious decisions to preserve links with Polish and Canadian culture. This is done in a variety of ways. As already discussed, to maintain their Polishness the participants speak Polish, have Polish friends, get involved in Polish-Canadian organizations, go to Polish church, etc. But being grounded in Canadian culture is also very important to them and most comment that they attend various cultural events, watch Canadian (not American, as emphasized by Elżbieta) television, listen to Canadian radio, read Canadian newspapers and magazines, and follow Canadian politics.

Norbert: Yeah, I do follow Polish politics as well as Canadian.

Elżbieta: I'm very political, so I follow politics all over the world but of course Canadian politics are for me most important and Polish too. And I'm pretty familiar with what's going on in both countries.

The above quotes also show that, in addition to being involved in the Polish community in Canada, an integral part of enacting Polishness is maintaining links with Poland, and all participants state that they follow Polish politics, sports, and other events and stay in touch with family and friends who live in Poland. Karol discusses how new technologies have changed the way he maintains these links. 
Karol: Especially in the last years when, you know, communication revolution started through internet and satellite TV [...] [E]verything changed because of that. And when we came to Canada it was different. There were newspapers available but not that many and they are not so actual so the news came kind of late. After years we got more and more Polish [...] and more and more magazines and newspapers coming, so basically right now we get all Polish magazines and newspapers at the same time as people in Poland. Even earlier because I can read news online and because of the time difference I know first what's going on there before they wake up.

Most of the participants comment on using online sources to read, listen to, and watch Polish content. They also comment on using email and Skype to stay in touch with family and friends. But this sudden influx of Polish content requires some of the participants to make certain choices.

Karol: I don't want to have Polish TV because it's pretty hard to follow two, like you have double lives, you know, to follow two countries, to follow two languages and, you know, because of time (you have work and family) so, I'd rather be Canadian and watch Canadian TV so my English is still improving all the time.

Karol specifically chooses to limit his exposure to Polish television to avoid being culturally and linguistically divided and to maintain his Canadian identity. It also seems that he views language as an important part of being Canadian. Later, it becomes apparent that he worries that excessive exposure to Polish content will negatively affect his English and, therefore, threaten his Canadian identity. Karol adds that he is more interested in Canadian issues because "this is where [he] lives." Marek echoes Karol's words, saying that he is more interested in local matters because there is "little [he] can 
do for Polish politics." Both Karol and Marek state that they are simply too busy to follow closely what is happening in Poland but that they do at least make an effort to "read the headlines" (Karol). Beniamin and Elżbieta also discuss the importance of following and being engaged in local matters.

For some of the participants, biculturalism is also reflected in other, more subtle choices. This is wonderfully illustrated by Kasia's discussion of using English and Polish names. When asked whether she has a Polish and an English name, she replied:

Kasia: Yes. Kasia. I go by Katherine at work. It depends who.... actually a couple of years ago I was visiting my cousin in Poland and I'm sitting there filling out postcards to send back to friends, family, work, etc. And I think I bought 5 or 6 and she's sitting there laughing at me across the table. And I'm like, what's so funny? She said, "You've signed every single card differently. One says Kaśka cause this is for your close friends. Kasia for your parents; Katherine for work and Katy for somebody else." So she 's just sitting there laughing about my split personality. So yeah, it does happen. But the funny thing is, the people who really, really know me well, my closest friends, they all know me as Kaśka - Canadian or Polish alike.

It may be argued that Kasia's choice of names reflects enactment of different personas (i.e. private vs. professional). In other words, she uses the diminutive of Katarzyna - Kasia/Kaśka with her most intimate friends and family, and Katherine and Katy with co-workers and English-speaking acquaintances. Interestingly, all of the adolescent participants discussed name choice in a similar manner though none of the adults did. Marek mentions that he uses Mark in a professional setting even when dealing with other Polish people as the name creates distance and formality. Beniamin talks about 
how he has recently changed his voicemail recordings from Ben to Beniamin because "that is [his] name," but then goes on to say that he has adopted Ben with Englishspeaking friends and colleagues because otherwise people call him Benjamin, which he hates. The above shows us that name choice is far from random and that it can be used to enact different identities.

Kasia's story alludes to the notion of a schizophrenic, split personality - echoing the enactment of different selves noted in memoirs of bilingual writers and some research on bilingualism (Pavlenko, 2006). This theme, however, was not limited to name choice. Beniamin describes acting and feeling like versions of himself in Polish versus Canadian contexts:

Beniamin: I find that when I do things with Canadians it's like a dif- like I have to change myself-[...] I feel a little bit more at home when I'm with the Polish crowd 'cause I know how to act and I know what the expectations are. When I'm around Canadians, it's just like I have to turn myself down [...]. [E]ven simple things like greeting, uhh, you know, like usually when you meet somebody, especially a woman colleague, you know, you give her the three kisses on each cheek, uhh, I would never do that with any of my Canadian friends [...] but I guess I've learned to accustom and I've adapted and [...] when I'm around Canadians I am the way they are and when I'm around Polish I feel myself, I mean, I feel like myself.

The notion of a dual identity is very pronounced in Beniamin's discussion, as is the idea that his Canadian identity is somehow artificial. For Beniamin, acting Canadian requires just that - acting. Though Marek and Kasia do not explicitly discuss this multiplicity of personality, it is arguably implied in their context-dependent name choice. 
Kasia also alludes to acting differently in different contexts but does not specifically describe what the differences are other than language use. She gives attending Polish mass as an example, saying that in that context one can only use Polish. Having said that, she claims that on a purely social level that duality disappears - she has a mixed network of friends and simply acts like 'herself', using both Polish and English. As already mentioned, none of the adult participants explicitly reported experiencing this identity split. It may be argued that, because of their age upon immigration, they are more firmly rooted in a single, Polish identity. It will be shown below, however, that the adult participants experience a duality in other ways.

\subsection{Social networks}

A preliminary look at the data reveals that there is a clear split in participants' social networks. This is particularly the case for the adult group whose intimate (exchange and passive) networks are predominantly Polish, and whose professional (interactive) networks are mostly Canadian. Perhaps the only exception here is Elżbieta who claimed to have a half-Polish, half-Canadian friendship network outside of work. As the interview progressed, however, it became clear that most of her Canadian friends are immigrant Canadians, not Anglo-Canadians. This is also the case for Kasia: "I would say fifty/fifty. Maybe fifty-five percent Polish, forty-five Canadian...well, other, I would say. Some of them, when you ask them to identify who they are, they'll mention some other nationality first and then Canadian." Later in the interview, Kasia admits that she only has two or three 'truly Canadian' friends who are third or fourth generation Canadians. Marek reports having many Polish-Canadian friends but says that since moving to the GTA his friendship networks have become more mixed. Beniamin has a group of Polish 
friends that he gets together with occasionally but spends most of his time with Canadians.

While both groups have split networks, the data clearly indicate that the network split is more pronounced for the adults. Throughout the interviews, both groups offer a number of explanations for this duality. The most straightforward reason given for having dual networks is that they are a continuation of initial support networks. In other words, having predominantly Polish exchange networks is partially an outcome of actions taken during the early stages of settlement.

Norbert: When we came here those 23, 24 years ago we didn't know any Canadians, any other people. We got involved with Polish organizations, Polish church, met Polish people. Those relations are still till this day. That's probably why. We basically keep our close group of friends and these are Polish friends we met 24 years ago.

Polish organizations, specifically the Polish church, are identified as having been key places for meeting other Polish immigrants during settlement. The church remains not only a place of faith and prayer for some of the participants (a place where they can express their faith in Polish), but also "a physical building" (Kasia) used to house meetings of various secular groups such as the Polish Scouts. But perhaps most importantly, the church is, for many, a place where they have met their friends more than twenty years ago. As Karol notes, these friendships are strong and intimate and the friends are "almost like family."

Marek also comments on how Polish friends he has in Canada have become closer than the family he has in Poland. Elżbieta talks about how the connection she has with her Polish friends differs from the one she has with other friends. 
Elżbieta: It's different because with all Polish friends [...] everybody has some story behind their immigration to Canada. So, it is very emotional. Not necessarily very pleasant but very emotional. With Canadians, it's a little bit...those relationships are built. We met at some point and because we met we built some friendship. Or, you know, events we're going together to....but that friendship, or those relationships are not very deep.

Elżbieta discusses that she shares with her Polish friends an image of Poland of her youth, of the best years of her life. These images of a lost country, of the Poland left behind, are integral elements in maintaining Polish social networks, bringing people closer together, creating 'deep' friendships through shared memories.

However, the choice of social networks is not only determined by initial support networks and shared images of the country of origin; there seem to be other factors at work. The adult participants comment on how their choice of networks had been limited by the unpleasant realities of immigration. For example, Karol discusses how most Polish immigrants, regardless of their level of education, had to perform "the worst jobs possible" at the beginning of their stay in Canada and have therefore been exposed to 'uneducated' Canadians with whom they had little in common. Elżbieta talks about some of her Polish friends who "don't have those avenues to Canadians" because of their jobs. Elżbieta: When you go to your work and you are among Polish people and you don't speak English while you are working ten hours a day, you are losing ten hours. When someone is driving a truck, they spend so much time on the road... when can they learn the language? That's the reality. You are coming home tired and now you are expected to learn English? No. 
Though she does not state so explicitly, it seems that Elżbieta considers language proficiency to be of paramount importance in moving beyond Polish networks. This is, of course, an uncontroversial position since making English-speaking friends without speaking English would be difficult for obvious reasons. Norbert agrees that language is a barrier in making Canadian friends but suggests that there is more to it than immigrants' inability to learn English:

Norbert: A lot of my friends were saying that, you know, we live in a British city, London and they don't really like immigrants here. It's hard to find a job, hard to find yourself a new social life among them because they tend to keep together, keeping us, as immigrants, on the outside and to a certain degree I agree with this. [...] But that started with language. That was the first thing we noticed, that you had that barrier. You tried to say something and people would be playing games - forcing you or putting you in a position where you're not comfortable because they knew you didn't know how to say it properly.

The above quotes illustrate that in some cases immigrants are limited in their choice of networks due to factors that are largely beyond their control. However, only Norbert commented on discrimination as being one of those factors. It is also interesting that only adult participants addressed these issues. This is likely an outcome of age of immigration and differences in socialization once in Canada. It can be assumed that the adolescent participants had more opportunities to meet Canadian peers and likely faced fewer barriers (including language), having completed high school and university education in Canada. This is, of course, reflected in their social networks which, though still Polish-dominant in the case of Marek and Kasia, are more mixed than those of the 
adults. Finally, here, as in previous sections, language plays a central role in shaping bicultural experience. It is worth mentioning, however, that while for the adults language is a barrier that limits social network choice, for Beniamin, network choice is made with language in mind.

Beniamin: Once I moved from Ottawa here to kinda GTA, which is Toronto area, umm, I know there's a lot of Polish people but again, I mean, I met my wife in Poland and I sponsored her here and I really wanted her to speak English so when she got here I kinda, kinda started hanging out with more of my Canadian friends [...] so my wife can learn English faster and better.

Clearly, Beniamin makes conscious decisions to choose social networks according to his language needs.

The above data suggest that language is therefore important in limiting and determining network choices. As will be shown below, language use is, in fact, at the centre of the participants' bicultural experience, and is an integral part of many of the themes discussed thus far.

\subsection{Language}

A re-examination of the aforementioned themes reveals that language is a thread that runs through categories and is likely, at least for these participants, the most salient characteristic of their bicultural identity. In the discussion of ethnic identity, most of the participants explicitly identified using Polish as a way of enacting Polishness in Canada. This suggests that language is a salient marker of ethnic identity for both groups. Conversely, using English is not explicitly mentioned as a marker of national identity. Despite this, the data suggest that the participants view English as an important 
characteristic of being a competent bicultural. Interestingly, this link is made only by the adult participants.

Norbert: Also for a lot of people, learning the language was another... language was a big barrier. Not even with communication but with understanding as well. So, over time you learn the language and you understand more what's around you.

Norbert discusses the above in reference to developing a cultural understanding, which, he suggests, cannot be achieved without learning the local language. Both Elżbieta and Karol comment on the importance of mastering English and often contrast themselves with 'those unintegrated' Poles who have not learned the language, who have not acquired the local culture. For the adult participants the acquisition of language is inseparable from the acquisition of culture and it is clear that they make conscious choices (such as Karol's decision not to watch Polish television) to maintain their English. There is, in fact, some fear of losing English present in the discourse of the adults.

Karol: I figured out that many people who follow Polish television and Polish media here in Canada, their Polish language is better and better, but their English is getting worse and some people who are staying here as long as me, their English is very poor because, you know, you don't listen, you don't use the language, you are losing the language.

This anxiety is not visible in the adolescent data. However, both Beniamin and Marek comment on first language attrition.

Beniamin: I am missing a lot of words, Polish words, and I wish I could [...] improve myself in that aspect. [...] I have to insert a lot of English words. [...] I mean I only have grade five Polish education, right, so I only know so many Polish words and even though 
I read a lot of articles and stuff in Polish, it is helping me but at the same time Ifind that, umm, I'd love to improve my Polish even better if it's possible.

Marek: I still can have a very normal conversation in Polish, just Polish. Although on occasion I see that it comes with some effort, especially when you want to be eloquent.

The contrast between the adults and adolescents is, of course, hardly surprising and is reflected in the self-assessment scores listed at the beginning of this section. All of the adults are more comfortable using Polish and all of the adolescents are equally comfortable using both (Marek and Kasia stated this explicitly and had rated their English and Polish almost identically), or have a preference for English (Beniamin's selfratings for Polish were significantly lower than for English). It is no wonder that one group is more worried about losing English and the other about losing Polish. However, these differences aside, both groups of participants comment on being 'linguistically incomplete' in at least one of their languages. For the adults, this incompleteness is solely limited to English (all adults gave themselves $7 / 7$ for Polish language skills) and is often expressed, particularly by Karol and Elżbieta, as language learning that is never complete:

Karol: Even now, you will hear a word or an expression that is new for you. So, it's a process of learning all the time and it will never stop for me.

Elżbieta: I learn from listening to people. But I wish I could spend 5 hours a week to go and practice my pronunciation, practice my accent. I don't have time.

The adolescent participants, on the other hand, at times find themselves between Polish and English and both Beniamin and Marek express the sensation of having two incomplete languages. 
Marek: But with English also, there is always something missing that I still should learn, but perhaps it's a matter of reading more books. I still have this habit of actually, if I don't understand a word, I'll just look it up right away because if I don't then I'll forget it but I still want to understand what specific words mean. But now, there's no time.

For Marek, much as was the case for the adults, learning English is a neverending process since something is "always missing". At the same time, as seen in his earlier comment, his Polish is slowly undergoing attrition. This is also true for Beniamin who finds that he is missing a lot of Polish words and has to fill in the gaps with English when communicating with Polish peers. But while his English is much stronger in most domains, he lacks various "childhood words" in his second language which he knows well in Polish. In fact, Beniamin's linguistic repertoire is characterized by various domain-specific features. He claims that, though he thinks "ninety percent in English", there are certain functions that he can perform (or think about) only in Polish and which will likely "never feel natural" in English. Interestingly, these functions seem to be formulaic - for example, math and formal prayer - and were likely memorized in early childhood. It is likely that these may seem more 'natural' in Polish simply because that is the context in which they were learned and performed throughout his life.

Other participants also comment on domain-specific language uses. Norbert talks about thinking about Canadian and American politics, and having a greater vocabulary related to these topics in English "because that's the language that information is in." Further, Norbert, Kasia, and Elżbieta comment on how they can more easily express work-related matters in English. Though this last point is once again easily explained with context-specific language use and acquisition, it also signifies something more 
important - that language use and knowledge are closely linked to the participants' social network patterns. But at an even deeper level, language use reflects the dichotomy between the private and the public self.

As already mentioned, language may both limit and influence the choice of social networks, particularly the exchange and passive networks. But in addition, language is a reflection of the social networks to which the participants belong. Of course, it is not at all surprising that their interactive networks are composed of Canadians and that they use English at work, at the bank, in the grocery store, etc. These are, after all, natural consequences of living in an English-speaking country, of living in ones' second language. What is significant is that the second language has not penetrated into the participants' most intimate networks. This is particularly true for the adult group, for whom Polish remains the language spoken at home and used with the closest of friends; it is the language of religion, literature, and personal reflection; it remains the language in which they can best express themselves, in which they "can describe $[\ldots]$ anything in beautiful words" (Elżbieta).

This is, to a lesser degree, also the case for the adolescent participants, especially Marek and Kasia. Though they have mastered English and show far more variation in langauge use than the adults, and though they proclaim that they are equally comfortable using and living in either language, Polish remains a more intimate language.

Marek: Well, definitely English is for work and also English is for some friends, etc. But Polish is more for friends and leisure. [...]Yeah, it's more private. [...] personal prayers, I do them sometimes in English but most of them I do in Polish. 
Kasia: I can pray in both languages but when I'm falling asleep and trying to pray I do it in Polish. I've gone to both masses, I've gone to communion in both churches, I've gone to confessions in both churches, so it doesn't bother me one way or the other. But when at home, my own private... I pray in Polish.

It may be argued that both groups of participants enact different identities in their respective languages. In other words, English is to a large extent associated with the participants' public persona while Polish remains closely linked with their non-public, intimate life. For these participants language use is split; it reflects the duality of their bicultural experience.

\section{Section 4: Discussion}

One of the purposes of this chapter was to illustrate the complexity of biculturalism and argue that existing typologies fail to adequately account for that complexity. For example, as already discussed, Phinney's model of cultural identity oversimplifies biculturalism because her dichotomy between ethnic and national identities is not always applicable. In fact, the constructs of both ethnic and national identity are problematic because they represent a monolithic view of culture. The analysis shows that the participants construct dynamic identities, at times choosing to identify with and participate in either Polish, or Canadian culture, at times with both, and at other times with neither. It also shows that the participants generally position themselves in opposition to the monocultural 'other', represented by unintegrated Poles and Poles living in Poland, as well as Anglo Canadians. In doing so, the participants truly highlight their biculturalism. 
Other typologies also inaccurately describe biculturalism. Trying to 'classify' these participants as blended or alternating biculturals is problematic. For example, Beniamin displays many characteristics of having a 'blended' bicultural identity - he has both Polish and Canadian friends, uses both languages, maintains ties with both cultures, identifies himself as Polish-Canadian and explicitly states, "I have one face. I try to be both Polish and Canadian at the same time." But, despite the claim that he is 'singular', Beniamin simultaneously experiences perhaps the most striking duality expressed by any of the participants, stating that he is not quite himself around Canadians (he has to 'act' Canadian) and that only around Polish people does he really 'feel like himself'. This implies that he is moving between cultures, between two different selves, which is a characteristic of alternating biculturalism. Though Beniamin's example is most noticeable, all participants show elements of having a single, integrated, hybrid identity coupled with a duality, a 'split' identity that is grounded in separate cultures.

This duality is experienced slightly differently by the adult and adolescent participants. For the adults it is most clearly illustrated by their 'choice' of social networks with a clear split between intimate Polish (or immigrant) networks and professional Canadian networks. This choice is reflected in their language use, which is also split between using Polish for most friends and family and English for work. While there is some evidence that language choice might determine network choice, it is not clear whether that is the case, or whether language choice is simply an outcome of choosing particular networks. Regardless, the two are undeniably closely interconnected. The adolescent participants express their bicultural duality in more complex and subtler ways. This is illustrated by Beniamin's discussion of 'acting' Canadian and by 
Marek and Kasia's context-dependent name choice. Further, the adolescents sometimes describe having two incomplete languages and, much like the adults, distinguish between an intimate language (Polish) and a public one (English).

The adolescents, however, are arguably less firmly grounded in Polish culture than the adults, and this is reflected both in their social networks (which are more mixed) and their language use (which is also more varied). Additionally, unlike the adults', the adolescents' ethnic identities do not appear to be grounded in memories of Poland. For the adults, this nostalgia is a salient part of their ethnic identities and also influences social network choice, acting as a base to create 'deep friendships', which centre around shared experiences.

In their discussion of social networks and identity, Mok et al. (2007) argue that "immigrants who accept the host culture into their subjective identities accept the host culture into their social networks" (p. 629). On the surface, it seems that even Elżbieta, the adult participant with the most mixed friendship networks, has not accepted the host culture into her 'subjective identity', as her non-Polish friends are other hyphenatedCanadians, not Anglo Canadians. This is also the case for the other participants who have Canadian social networks. These networks do, however, reflect the participants' view of Canada as a multicultural nation. This was one of the most consistent themes to emerge from the data: all of the participants commented on Canadian diversity and most (especially the adult participants) defined Canadians as being from somewhere else first. The participants are, therefore, just like the other Canadians they know and their social networks are composed of the multicultural members of the host society. 
There was a clear connection between defining Canada and Canadians this way and feeling a sense of belonging, feeling Canadian. Most of the participants commented on the positive aspects of Canadian multiculturalism saying that "it's easy to be Polish or multicultural in Canada" (Kasia). Consequently, reports of inclusion and acceptance far outweighed reports of discrimination. This was particularly the case for the participants who had lived in Germany prior to coming to Canada - they felt that Canada was far more accepting of diversity than Germany. This might be an outcome of the divergent citizenship policies employed by the two countries (Koopmans, Statham, Giugni, \& Passy, 2005); however, further speculation on the topic falls beyond the scope of this paper. Regardless, it is clear that context plays an important role in determining the type of biculturalism developed by immigrants. The data suggest that Canada provides immigrants with a multicultural 'space' conducive to being openly bicultural.

There may also exist a connection between Canadian multiculturalism and the participants' positive sense of ethnic identity. Both groups commented that they were proud to be Polish and defined their ethnic group in positive ways. They also stated that Polish immigrants are viewed favourably by other Canadians. While this positive selfdefinition is likely connected to the acceptance of diversity in Canada, it is also an outcome of the fact that the participants viewed their group as well-educated and adaptable (able to integrate well into Canadian society).

Integration was particularly important for the adult participants, who repeatedly defined themselves in contrast to the unintegrated immigrants. For them, being bicultural was equivalent to being integrated, culturally and socioeconomically. In addition, for the adults, the most important indicator of biculturalism/integration was the ability to use 
English, and it was clear that they made conscious decisions to maintain and improve their English. At the same time, using Polish was arguably the most salient characteristic of ethnic identity for both groups. Overall, language use was perhaps the most important aspect of participants' biculturalism.

Could these participants, then, be called, in LaFromboise et al.'s words, competent biculturals who exist comfortably in two cultures? Or, is their biculturalism a source of pain, a personality split that forever sentences them to an existence between cultures and renders everything relative and incomplete? The data examined here seem to suggest that it is the former, rather than the latter though this 'comfort' is not entirely free of certain splits and dualities.

All of the participants seem to have integrated well into Canadian society. But a quick glance at the biographical data reveals that, at least for the adults, this may have come at a cost, as there is a noticeable discrepancy between their level of (Polish) education and the jobs they perform in Canada. And for at least one of them, there is a slight sense of loss and maybe a hint of regret:

Norbert: You have to remember that in Poland we have encountered a lot of changes and these changes were tremendous. We don't have socialism over there anymore; we have free markets and with the free market a lot of changes happened, changes that basically eliminated a lot of differences between Poland and Canada. So, because of that, when you go there you look at the people and things around, how the economy grows and develops, you, again, you think that a long time ago you left something which right now is equal to what you have. Of course, you cannot forget that 20 years passed and in our lifetime we are unable to move back in time. But again, going there, one of the first 
feelings is that you have left part of your life and relatives there [...] There was a reason why we left Poland a long time ago and that reason, basically, no longer exists.

Nevertheless, beyond fleeting moments of nostalgia and occasional expressions of loss and regret, the participants seem content having a "foot in each" culture (Norbert) and make no negative comments regarding their jobs in Canada. In fact, most of the participants celebrate biculturalism, saying that it allows them to draw the best from both worlds and that bicultural immigrants are more accepting of cultural differences than monoculturals. Inherent in their experience is the enactment of a duality, but this duality is not 'schizophrenic', it is not an identity crisis, but rather an inherent part of being a competent bicultural. 


\section{CHAPTER V: CONCLUSION}

This study had several objectives. These included (1) examining the existing work on biculturalism to see whether the literature sufficiently accounts for the biculturalism of my participants, (2) investigating how the six Polish biculturals considered in this study negotiate and construct their identities, and (3) determining what role language plays in their bicultural experience and identity formation.

Data analysis showed that the theoretical and quantitative models used to study biculturalism have a number of limitations. More specifically, these models alone were not sufficient for describing the bicultural experience of my participants. To effectively analyze the interview data and account for the complexity of biculturalism, I needed to look beyond the literature in social psychology, supplementing it with research on social networks, bilingualism, and language and identity.

The models were, in part, insufficient because they were too static - being bicultural involves the negotiation of multiple, dynamic cultural identities; it requires existing in two worlds and being both singular and split. Though these characteristics of bicultural identity may seem contradictory and have, in the past, been equated with a psychological crisis, this does not seem to be the case for my participants, who view their biculturalism in a more positive light.

The participants' bicultural identities are characterized by a number of traits. The analysis showed that they enact both a Polish and a Canadian identity, as well as a hybrid Polish-Canadian identity. To 'remain' Polish in Canada they speak Polish, have Polish friends, get involved in the Polish community, and maintain links with Poland through modern media. For these participants, being Canadian involves participating in cultural 
events, being aware of local issues, and being tolerant and accepting of diversity. It also involves being hyphenated, and the participants construct their Polish-Canadian identities in opposition to the monoculturalism of unintegrated immigrants, Poles (in Poland), as well as Anglo Canadians. In fact, for these participants, being Canadian means being hyphenated, and this idea is reflected in how they construct their bicultural identities in opposition to monoculturalism, in how they explicitly define being Canadian as being hyphenated. It is also reflected in their choices of intimate social networks, which are largely composed of hyphenated Canadians.

The bicultural experience of these participants is also marked by a duality that is both actively maintained and passively experienced. The participants make conscious decisions to remain grounded in two worlds; they also make important decisions about limiting exposure to cultural content, particularly Polish content, since it is seen as a threat to their Canadian identities. This duality is further illustrated by their social network choice and language use patterns, and the two may, in fact, be closely related.

It is not clear whether language determines, or simply reflects, participants' social network choice. It is clear, however, that, particularly for the adults, it represents the division between the private and the public sphere, each characterized by its respective language - Polish and English. Language choice further highlights this dichotomy, showing that some of the participants choose to use Polish in intimate settings (with close friends and family) and situations (personal prayer). The adolescents, for example, choose between using Polish and English names depending on the context and the relationship to the interlocutors. Language use is also the most salient aspect of the participants' ethnic identities. It is also the most salient characteristic of the adult 
participants' bicultural identities, being identified as the most important element of integration. The adult participants often describe language acquisition as inseparable from cultural acquisition. Clearly, language plays an important role in the life of these participants and is closely linked to their biculturalism.

As already mentioned, the bicultural experience of these participants is marked by a dual existence, but this split between personal and public selves, between Polish and Canadian identities is not a source of pain. The data suggest that one of the reasons why the participants are so 'comfortably' bicultural is due to the type of environment in which they live - the Canadian multicultural space and the large Polish community within it. In other words, the participants' perception of Canada as a diverse nation helps them feel included, and likely results in a positive self-definition as members of the Polish ethnic group. The large Polish community offers opportunities to be involved in PolishCanadian organizations, practice religion in Polish, and develop Polish social networks.

For these participants, Canada is a place where they can be Polish-Canadian without worrying about discrimination, a place where they can freely express their hyphenated identities. To emphasize this, they contrast Canadian multiculturalism with the monoculturalism found in Germany, a country that did not offer that inclusion to the three participants who lived there.

Canadian multiculturalism is also contrasted with monocultural Poland, particularly by the adult participants. They admit that living in Canada has changed them, made them different from monocultural Poles. Once more, these changes revolve around the acceptance of diversity in Canada. The participants discuss how they have become more tolerant, more aware and accepting of cultural differences, differences which were 
largely missing in the monocultural Poland of their youth. This suggests that there are a number of (interconnected) ways in which the image of Canadian multiculturalism influences bicultural identity formation. On the one hand, Canada is seen as an environment in which diversity is accepted and even celebrated. Because of this, the Polish Canadians in my sample feel included and free to celebrate their hyphenated identities. On the other hand, they are faced with many other cultures and many other cultural perspectives. This, in turn, requires a re-evaluation of one's cultural norms and the change in perceptions discussed by the participants - that there is not just a single way of looking at the world. This understanding is expressed as becoming more tolerant and accepting of other cultures.

Perhaps one of the reasons that most of the participants have social networks composed of hyphenated Canadians is related to this enhanced understanding and acceptance. This is discussed most clearly by Kasia: "I do find a difference in the way I interact with people who are immigrants. [...] I think that people who are immigrants, regardless what background they come from, they're more accepting of your different ways of doing things.“

The contrast between biculturalism and monoculturalism is one of the most common strategies the participants use in constructing their identities. In establishing their biculturalism, the participants constantly distinguish between themselves and monocultural individuals and contrast multicultural Canada with monocultural countries. I would argue that their bicultural identities are a reflection of their image of Canadian multiculturalism, of Canadian culture - accepting of diversity, multiple, dynamic, and hard to define. 
The investigation of biculturalism presented in this paper is, of course, only a fraction of a larger whole. A more detailed account could have been produced using various sources of data rather than just interview and short questionnaire data. Combining these with observations, written reflections and other sources would have revealed more about how these participants construct their identities.

Additionally, the sample size - three participants in each group - is small even for a qualitative study, and certainly too small to make any generalizations or valid intergroup comparisons. However, my aims in conducting the study were not to generalize to the Polish-Canadian population in Canada, but to try and describe the biculturalism of these participants. Therefore, this study was a preliminary look at Polish biculturalism in Canada and was meant to suggest possible trends and themes that could be explored in future research. Additionally, this sample was very specific, being composed of well-educated and integrated Polish-Canadians. Biculturalism might be expressed differently by unintegrated immigrants or members of visible minorities, for whom images of Canada may be less positive.

In some ways, then, what I have presented above is, much like most current research on biculturalism, an oversimplification of a complex issue. I hope, however, that the information presented will offer some insights into the bicultural experience of Polish-Canadians. Finally, I wonder how different the data would be - if at all - if the interviews were conducted using that more intimate language. 


\section{REFERENCES}

Benet-Martínez, V., \& Haritatos, J. (2005). Bicultural identity integration (BII):

Components and psychosocial antecedents. Journal of Personality, 73(4), 10151050.

Benet-Martínez, V., Leu, J., Lee, F., \& Morris, M. W. (2002). Negotiating biculturalism:

Cultural frame switching in biculturals with oppositional versus compatible cultural identities. Journal of Cross-cultural Psychology, 33(5), 492-516.

Berry, J. W. (1980). Social and cultural change. In H. C. Triandis \& R. W. Brislin (Eds.), Handbook of cross-cultural psychology: Social psychology (Vol. 5) (pp. 211279). Boston: Allyn and Bacon.

Berry, J. W. (1984). Multicultural policy in Canada: A social psychological analysis. Canadian Journal of Behavioural Science, 16(4), 353-370.

Berry, J. W. (1997). Integration, acculturation, and adaptation. Applied Psychology: An International Review, 46, 5-34.

Berry, J. W. (2005). Acculturation: Living successfully in two cultures. International Journal of Intercultural Relations, 29, 697-712.

Boski, P. (2008). Five meanings of integration in acculturation research. International Journal of Intercultural Relations, 32, 142-153.

Cachelin, F. M., Phinney, J. S., Shug, R. A., \& Striegel-More, R. H. (2006). Acculturation and eating disorders in a Mexican American community sample. Psychology of Women Quarterly, 30(4), 340-347.

Citizenship and Immigration Canada. (2011, Feb. 13). [News release] Canada welcomes highest numbers of legal immigrants in 50 years while taking action to maintain 
the integrity of Canada's immigration system. Retrieved from http:/www.cic.gc.ca/english/department/media/releases/2011/2011-02-13.asp

Creswell, J.W. (1994). Research design: Qualitative and quantitative approaches. London: SAGE Publications.

Dandy, J., Durkin, K., McEvoy, P., Barber, B., \& Houghton, S. (2008). Psychometric properties of multigroup ethnic identity measure (MEIM) scores with Australian adolescents from diverse ethnocultural groups. Journal of Adolescence, 31, 323335.

David, E. J. R., Okazaki, S., \& Saw, A. (2009). Bicultural self-efficacy among college students: Initial scale development and mental health correlates. Journal of counseling Psycology, 56(2), 211-226.

De Korne, H., Byram, M., \& Fleming, M. (2007). Familiarising the stranger: Immigrant perceptions of cross-cultural interaction and bicultural identity. Journal of Multilingual and Multicultural Development, 28(4), 290-307.

Edwards, J. (2009). Language and identity: An introduction. Cambridge, MA: Cambridge University Press.

Fishman, J. A. (1989). Language and ethnicity in minority sociolinguistic perspective. Philadelphia: Multilingual Matters.

Fishman, J. A. (1994). The truth about language and culture (and a note about its relevance to the Jewish case). International Journal of the Sociology of Language, 109, 83-96.

Grosjean, F. (2010). Bilingual life and reality. Cambridge: Harvard University Press. 
Haritatos, J., \& Benet-Martínez, V. (2002). Bicultural identities: The interface of cultural, personality, and socio-cognitive processes. Journal of Research in Personality, $36,598-606$.

Hoffman, E. (1989). Lost in translation: A life in a new language. New York: Penguin Books.

Hong, Y., Morris, M. W., Chiu, C., \& Benet-Martínez, V. (2000). Multicultural minds: A dynamic constructivist approach to culture and cognition. American Psychologist, 55(7), 709-720.

Joseph, J. E. (2004). Language and identity: National, ethnic, religious. New York: Palgrave Macmillan.

Joseph, J. E. (2006). Identity and language. In Encyclopedia of language and linguistics (2nd ed.) (Vol. 1, pp. 486-492). Oxford: Elsevier.

Kosic, A. (2002). Acculturation attitudes, need for cognitive closure, and adaptation of immigrants. The Journal of Social Psychology, 142(2), 179-201.

Koopmans, R., Statham, P., Giugni, M., \& Passy, F. (2005). Contested citizenship: Immigration and cultural diversity in Europe. Minneapolis: University of Minnesota Press.

LaFromboise, T., Coleman, H. L. K., \& Gerton, J. (1993). Psychological impact of biculturalism: Evidence and theory. Psychological Bulletin, 114(3), 395-412.

Lanza, E., \& Svendsen, B. A. (2007). Tell me who your friends are and I might be able to tell you what language(s) you speak: Social network analysis, multilingualism, and identity. International Journal of Bilingualism, 11(3), 275-300. 
LeCompte, M.D., \& Preissle, J. (1993). Ethnography and qualitative design in educational research. San Diego: Academic Press.

Luna, D., Ringberg, T., \& Peracchio, L. A. (2008). One individual, two identities: Frame switching among biculturals. Journal of Consumer Research, 35, 279-293.

Lustanski, J. (2009). Polish Canadians and Polish immigrants in Canada: Self-identity and language attitude. International Journal of Sociology of Language, 199, 3961.

May, S. (2001). Language and minority rights: Ethnicity, nationalism and the politics of language. Harlow: Pearson Education.

McCracken, G. (1988). The long interview. London: SAGE Publications.

Merriam, S.B. (2009). Qualitative research: A guide to design and implementation. San Francisco: Jossey-Bass.

Miramontez, D. R., Benet-Martínez, V., \& Nguyen, A. D. (2008). Bicultural identity and self/group personality perceptions. Self and Identity, 7, 430-445.

Mok, A., \& Morris, M. W. (2009). Cultural chameleons and iconoclasts: Assimilation and reactance to cultural cues in biculturals' expressed personalities as a function of identity conflict. Journal of Experimental Social Psychology, 45, 884-889.

Mok, A., Morris, M. W., Benet-Martínez, V., \& Karakitapoğlu-Aygün, Z. (2007). Embracing American culture: Structures of social identity and social networks among first-generation biculturals. Journal of Cross-cultural Psychology, 38(5), 629-635.

Padilla, A. M. (2006). Bicultural social development. Hispanic Journal of Behavioral Sciences, 28(4), 467-497. 
Park, R. E. (1928). Human migration and the marginal man. The American Journal of Sociology, 33(6), 881-893.

Patton, M.Q. (2002). Qualitative research \& evaluation methods ( $3^{\text {rd }}$ ed.). London: SAGE Publications.

Pavlenko, A. (2005). Emotions and multilingualism. Cambridge: Cambridge University Press

Pavlenko, A. (2006). Bilingual selves. In A. Pavlenko (Ed.), Bilingual minds: Emotional experience, expression and representation (pp. 1-33). Clevedon: Multilingual Matters Ltd.

Phinney, J. S. (1989). Stages of ethnic identity development in minority group adolescents. Journal of Early Adolescence, 9(1-2), 34-49.

Phinney, J. S. (1990). Ethnic identity in adolescents and adults: Review of research. Psychological Bulletin, 108(3), 499-514.

Phinney, J. S. (1992). The multigroup ethnic identity measure: A new scale for use with diverse groups. Journal of Adolescent Research, 7(2), 156-176.

Phinney, J. S., Berry, J. S., Vedder, P., \& Liebkind, K. (2006). The acculturation experience: Attitudes, identities, and behaviors of immigrant youth. In J. W. Berry, J. S. Phinney, D. L. Sam, \& P. Vedder (Eds.), Immigrant youth in cultural transition: Acculturation, identity, and adaptation across national contexts (pp. 71-117). London: Lawrence Erlbaum.

Phinney, J. S., Cantu, C. L., \& Kurtz, D. A. (1996). Ethnic and American identity as predictors of self-esteem among African American, Latino, and White adolescents. Journal of Youth and Adolescence, 26(2), 165-185. 
Phinney, J. S., \& Devich-Navarro, M. (1997). Variations in bicultural identification among African American and Mexican American adolescents. Journal of Research on Adolescents, 7(1), 3-32.

Phinney, J. S., Horenczyk, G., Liebkind, K., \& Vedder, P. (2001). Ethnic identity, immigration, and well-being: An interactional perspective. Journal of Social Issues, 57(3), 493-510.

Phinney, J. S., \& Ong, A. D. (2007). Conceptualization and measurement of ethnic identity: Current status and future directions. Journal of Counseling Psychology, 54(3), 271-281.

Ryan, L. (2010). Becoming Polish in London: Negotiating ethnicity through migration. Social Identities, 16(3), 359-376.

Statistics Canada (2011). 2006 census Canada. Available from http://www12.statcan. gc.ca/census-recensement/2006/dp-pd/index-eng.cfm

Strauss, A., \& Corbin, J. (1998). Basics of qualitative research: Techniques and procedures for developing grounded theory. London: SAGE Publications.

Tajfel, H., \& Turner, J. C. (1986). The social identity theory of intergroup behavior. In S. Worchel \& W. G. Austin (Eds.), Psychology of intergroup relations (pp. 7-24). Chicago: Nelson-Hall Publishers.

Tartakovsky, E. (2009). Cultural identities of adolescent immigrants: A three-year longitudinal study including the pre-migration period. Journal of Youth and Adolescence, 38, 654-671.

Temple, B. (2010). Feeling special: Language in the lives of Polish people. The Sociological Review, 58(2), 286-304. 
Tesch, R. (1990). Qualitative research: Analysis types and software tools. New York: Falmer

Umaña-Taylor, A. J., \& Fine, M. A. (2001). Methodological implications of grouping Latino adolescents into one collective ethnic group. Hispanic Journal of Behavioral Sciences, 23, 347-362.

United Nations (2009a). International migration report 2006: A global assessment. Retrieved from http://www.un.org/esa/population/publications/2006_ MigrationRep/report.htm

United Nations (2009b). [Wall chart] International migration report 2009. Retrieved from http://www.un.org/esa/population/publications/2009Migration_ Chart/2009Itt Mig_chart.htm

Warriner, D. S. (2007). Transnational literacies: Immigration, language learning, and identity. Linguistics and Education, 18, 201-214.

Wei, L., Milroy, L., \& Ching, P. S. (2007). A two-step sociolinguistic analysis of codeswitching and language choice: the example of a bilingual Chinese community in Britain. In L. Wei (Ed.), The bilingualism reader (2nd ed.) (pp. 139-158). London: Routledge.

Weisman, E. M. (2001). Bicultural identity and language attitudes: Perspectives of four Latina teachers. Urban Education, 36(2), 203-225.

Zajacova, A. (2002). Constructing the reality of the immigrant life. Journal of Social Distress and the Homeless, 11(1), 69-79. 
Canada's Capital University

\section{Consent Form}

Title of research project: Biculturalism within multiculturalism: A qualitative study of two groups of Polish Canadians

Date of ethics clearance: 2 December 2010

Ethics clearance for collection of data expires: 31 May 2011

I, , have read the information below and volunteer to participate in a project on immigration, language, identity and integration of Polish immigrants to Canada.

\section{Description of study:}

\subsection{Summary of aims}

The aim of this research project is to gain insight into the formation of identity of Polish immigrants who arrived in Canada as adolescents or adults. More specifically, the study hopes to explore how identity formation is related to language use and integration of Polish immigrants into the Canadian society.

\subsection{Participants}

Two participant groups will be interviewed: Polish immigrants who arrived in Canada as adolescents (aged 11-16 at arrival), and Polish immigrants who arrived in Canada as adults (aged 20 or more at arrival). Only participants who have lived in Canada for at least 10 years will be considered in this study.

\subsection{Methodology}

Data will be collected during two interviews conducted with each participant. Each interview will take about half an hour to an hour. The interviews will be recorded using an $\mathrm{mp} 3$ voice recorder and then transcribed by the researcher.

\section{Data collection and storage}

All data will be recorded using an mp3 voice recorder and stored on a password-protected external hard drive kept at a secure location in the residence of the researcher. All transcribed text will use pseudonyms to ensure the anonymity of the participants. Only the researcher will have access to data. 
The interviews will be stored in the manner mentioned above indefinitely as they may be used in future projects that are related to the same topic. The interviews will not be used for research projects that are not related in purpose and topic to the present project.

\section{Participation}

\subsection{Participation and withdrawal}

Participation in the project is entirely voluntary. Participants have the right to withdraw from the project within $\mathbf{3 0}$ days of receiving the transcripts of the interview. In such a case, the participants need to notify the researcher of their intent to withdraw from the project through email, over the telephone, or in person. In case of withdrawal all data pertaining to the participant will be destroyed by deleting the files from the passwordprotected external hard drive.

Participants have the right to refuse to answer any questions asked during the interview and can request to have text stricken from data during or after the interview.

\subsection{Anonymity}

A number of steps will be taken to ensure participant anonymity during the research process and publication. Pseudonyms will be used in text transcriptions and discussions of project as well as publication of research. These pseudonyms will be used again in any future publications related to this data. It is important to note, however, that due to the methods used to identify and recruit participants for this study, total anonymity cannot always be guaranteed. Because the researcher used elements of snowballing in participant identification (identifying participants through acquaintances) there is a chance that participants may be identified by these acquaintances based on personal data given (age, length of stay in Canada, educational background, etc.).

\subsection{Risk}

There is some risk that the information disclosed during the interview might be personal and embarrassing. Participants should be aware that the interview can be stopped any time the topic discussed causes personal discomfort and that participants can refuse to answer any question and/or can strike any information from the record.

\section{Contact information}

Prof. Antonio Gualtieri - REB Chair; tel: 613-520-2517; email: ethics@carleton.ca

Dr. Ellen Cray - research supervisor; tel: 613-520-2600 x.2806; email: ellen_cray@carleton.ca

Andrzej Szeib - researcher; tel: email: aszeib@connect.carleton.ca

This project has been reviewed and cleared by the Carleton University Research Ethics Board 613-520-2517 or ethics@carleton.ca 


\section{APPENDIX B}

\section{Biographical Questionnaire:}

1. When did you arrive in Canada?

2. How old were you when you arrived?

3. How long have you been in Canada?

4. Could you briefly describe your education in Poland (level, area of study, etc.)

5. Did you work in Poland? If so, what was your profession?

6. Did you attend school in Canada? If so, at what level? What did you study?

7. Did you study English before coming to Canada? For how long? Formal/informal?

8. Did you study English when you arrived in Canada? (LINC, ESL, formal/informal)

9. How would you rate your English language skills from 1 (poor) to 7 (excellent)?

speaking -

listening - reading -

writing -

10. How would you rate your Polish language skills from 1 (poor) to 7 (excellent)?

speaking -

listening - reading -

writing - 


\section{APPENDIX C}

\section{Part I.}

1. If asked what your nationality is, what would you say? Why?

2. What does it mean to be Polish? or What is it that you do that's Polish?

3. What is it that you do that's Canadian?

4. Would you say that you interact more with Poles than Canadians?

\section{Part II.}

5. What are some differences between Poles/Canadians, between Polish and Canadian cultures?

6. Are you proud to be Polish, Polish-Canadian, Canadian?

7. How, in your opinion, are Poles/Polish immigrants perceived by Canadians? Why do you think that?

8. How are Canadians perceived by Polish immigrants?

\section{Part III.}

9. Do you feel like you have a Polish and a Canadian identity?

10. Do you feel like you are a part of a combined culture, or like someone moving between two cultures?

11. Do you have a Polish and a Canadian name? When do you use them?

12. Do you feel comfortable living in Canada? Do you consider Canada your home, your country?

13. Would you like to return to Poland? Why? Why not?

14. Do you feel more comfortable in Poland or Canada? Why?

\section{Part IV.}

15. Is using Polish important to you? Why?

16. Do you feel more comfortable using Polish or English?

17. Have you had any negative experiences using English?

18. Is your knowledge/use of English in any way limiting your ability to express your 'true' self?

19. Do you feel like a different person when using different languages? 


\section{Ethics Clearance Form}

This is to certify that the Carleton University Research Ethics Board has examined the application for ethical clearance. The REB found the research project to meet appropriate ethical standards as outlined in the Tri-Council Policy Statement: Ethical Conduct for Research Involving Humans and, the Carleton University Policies and Procedures for the Ethical Conduct of Research.

\section{$X$ New clearance}

$\square$ Renewal of original clearance

\section{Original date of clearance:}

Date of clearance

Student researcher

Status

Faculty supervisor

Department

Funding status

Title of project
2 December 2010

Andrzej Szeib

M.A. student

Professor Ellen Cray

School of Linguistics and Language Studies

Not funded

Immigration, language, identity and integration: A case study of Polish adolescent and adult immigrants to Canada

\section{Clearance expires: 31 May 2011}

\section{All researchers are governed by the following conditions:}

Annual Status Report: You are required to submit an Annual Status Report to either renew clearance or close the file. Failure to submit the Annual Status Report will result in the immediate suspension of the project. Funded projects will have accounts suspended until the report is submitted and approved.

Changes to the project: Any changes to the project must be submitted to the Carleton University Research Ethics Board for approval. All changes must be approved prior to the continuance of the research.

Adverse events: Should any participant suffer adversely from their participation in the project you are required to report the matter to the Carleton University Research Ethics Board. You must submit a written record of the event and indicate what steps you have taken to resolve the situation.

Suspension or termination of clearance: Failure to conduct the research in accordance with the principles of the Tri-Council Policy Statement: Ethical Conduct for Research Involving Humans and the Carleton University Policies and Procedures for the Ethical Conduct of Research may result in the suspension or termination of the research project.

Lestie J. MácDb́rald-Hicks -

Research Ethics Board Coordinator

For the Chair of the Carleton University Research Ethics Board

Prof. Antonio Gualtieri 